Portland State University

PDXScholar

Spring 7-12-2019

\title{
Situational Context of Police Use of Deadly Force: a Comparison of Black and White Subjects of Fatal Police Shootings
}

Shana Lynn Meaney Ruess

Portland State University

Follow this and additional works at: https://pdxscholar.library.pdx.edu/open_access_etds

Part of the Criminology and Criminal Justice Commons, and the Law and Race Commons Let us know how access to this document benefits you.

\section{Recommended Citation}

Ruess, Shana Lynn Meaney, "Situational Context of Police Use of Deadly Force: a Comparison of Black and White Subjects of Fatal Police Shootings" (2019). Dissertations and Theses. Paper 5136. https://doi.org/10.15760/etd.7015

This Thesis is brought to you for free and open access. It has been accepted for inclusion in Dissertations and Theses by an authorized administrator of PDXScholar. Please contact us if we can make this document more accessible: pdxscholar@pdx.edu. 
Situational Context of Police Use of Deadly Force:

A Comparison of Black and White Subjects of Fatal Police Shootings

by

Shana Lynn Meaney Ruess

A thesis submitted in partial fulfillment of the requirements for the degree of

\author{
Master of Science \\ in \\ Criminology and Criminal Justice
}

Thesis Committee:

Brian Renauer, Chair

Mark Leymon

Mauri Matsuda

Portland State University

2019 
(C) 2019 Shana Lynn Meaney Ruess 


\begin{abstract}
Police use of deadly force is an understudied yet deeply important issue in our society. Recent years have seen a dramatic increase in public concern over use of deadly force, particularly when that force is used against people of color. Due to the relative low frequency of deadly force incidents, little is known about when such force is used, or who it is used on. Recent studies have found a racial disparity between white and black subjects of deadly force, with black subjects significantly over represented as a proportion of the population. This study further expands our understanding of police use of deadly force, specifically the situational context of its use against white and black subjects. We use 100 random cases from the Washington Post Fatal Force data set and conduct a content analysis on this sample to identify data on multiple possible situational factors. This exploratory study found several important differences between situations involving a white or black subject of a deadly police shooting. Black subjects are on average seven years younger than white subjects. Black subjects are statistically more likely to be killed following contact initiated by an officer, such as a traffic or pedestrian stop. White subjects are more likely to be killed following contact initiated by dispatchers or courts, such as a call for service or when serving a warrant. Differences were also found related to the reasons for contact, the location of the incident, and the forms of resistance from the subject. This study provides validation to claims that police use deadly force differently between black and white subjects and implicates police officer training and discretion in the racial disparity of use of deadly force.
\end{abstract}




\section{Table of Contents}

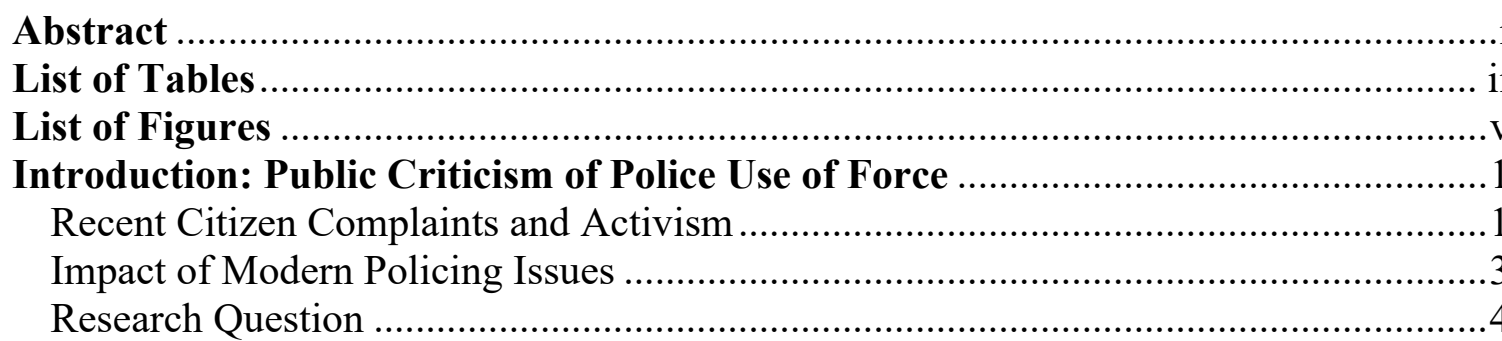

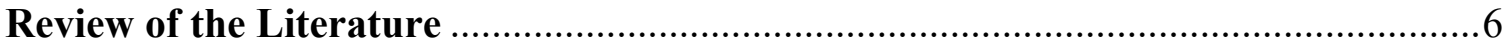

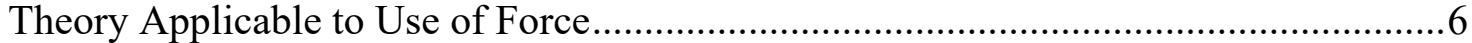

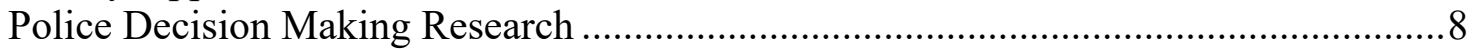

Decision to Shoot Experiments.............................................................................. 9

Racial Bias in Police Decision Making Research.................................................... 10

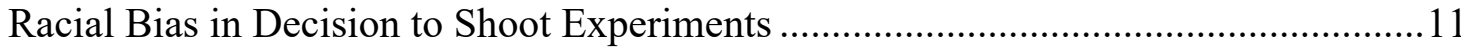

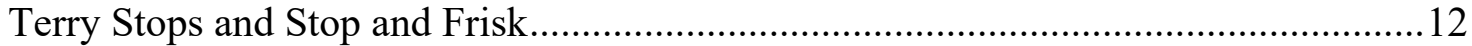

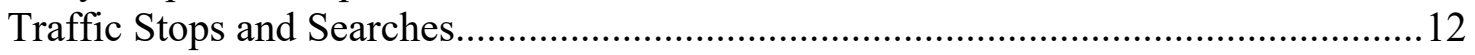

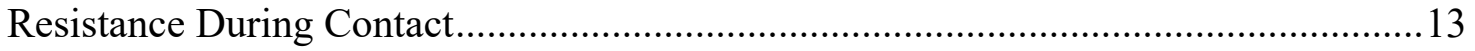

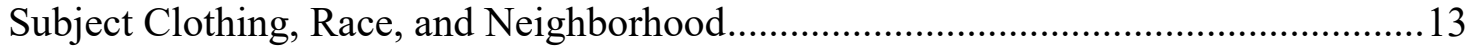

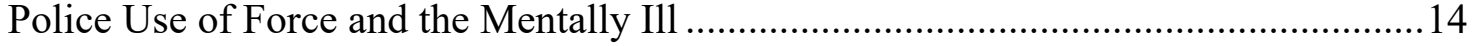

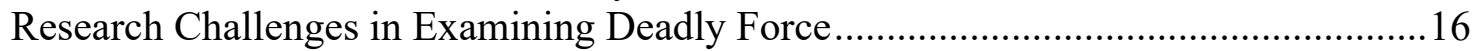

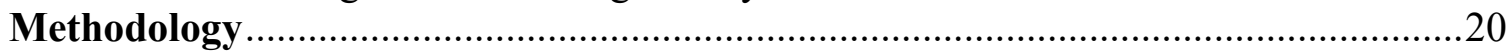

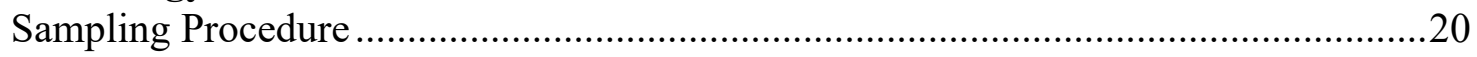

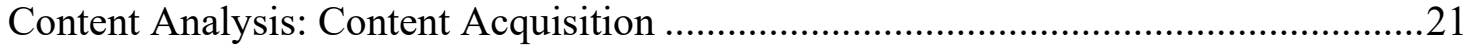

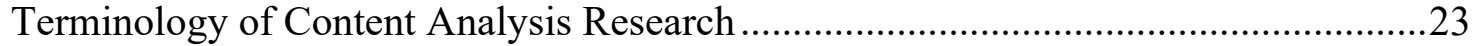

Content Analysis Process..................................................................................25

Phase One: Exploratory analysis using manifest coding ......................................25

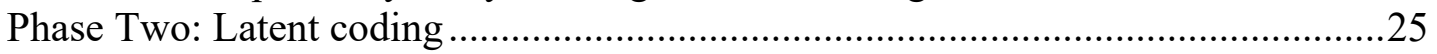

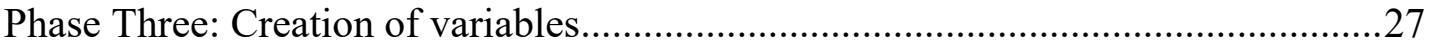

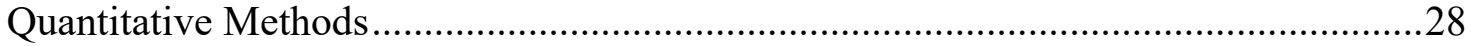

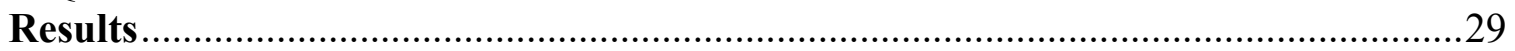

Content Analysis and Variable Construction............................................................29

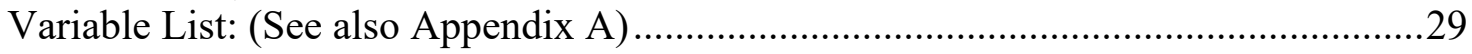

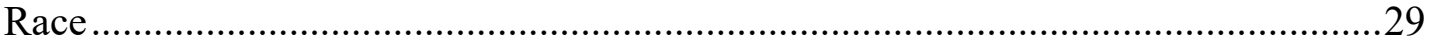

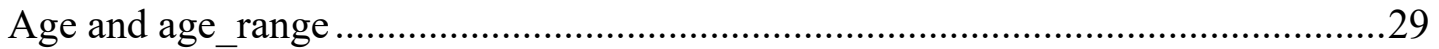

Time_of_day and time_period .......................................................................... 30

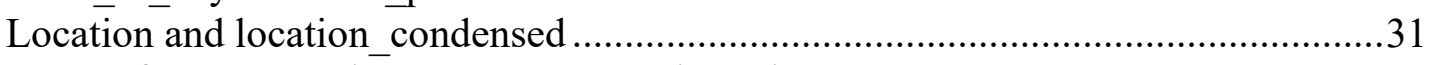

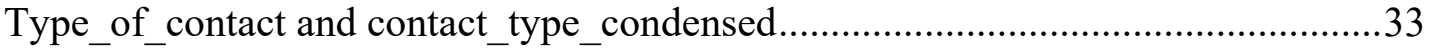

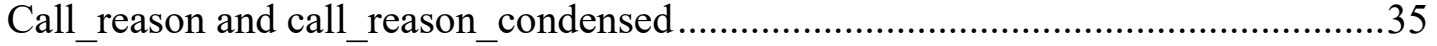

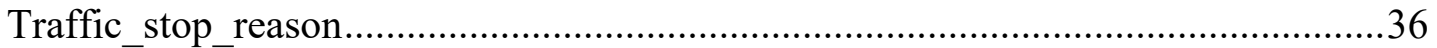

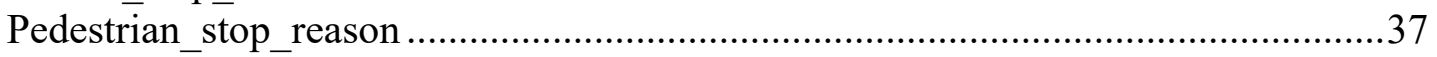

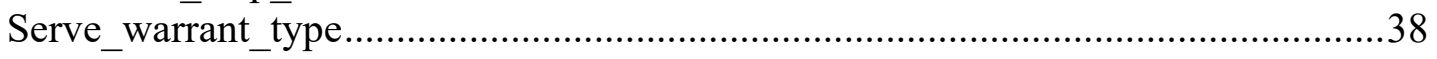

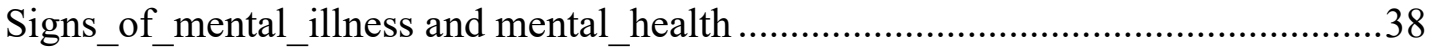

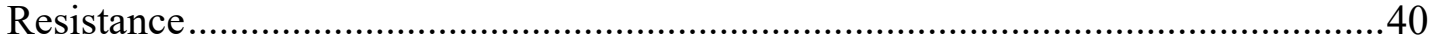

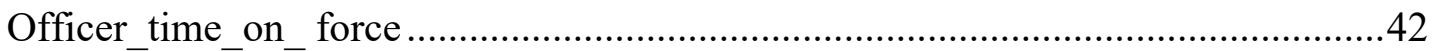

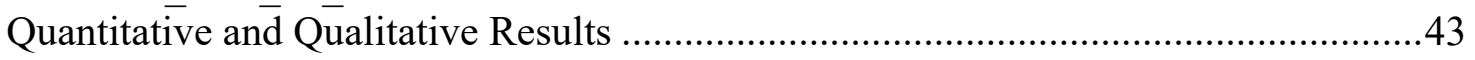




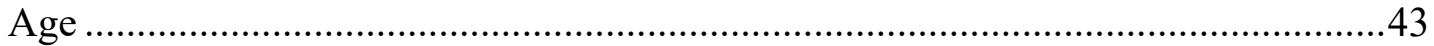

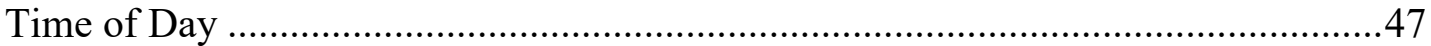

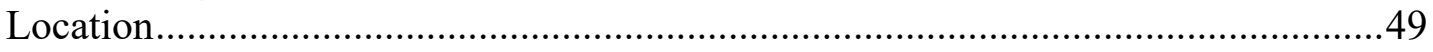

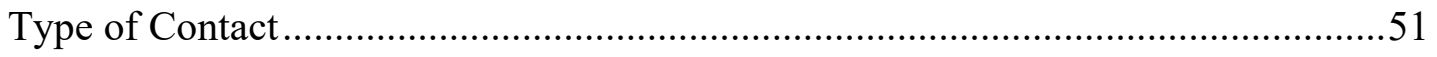

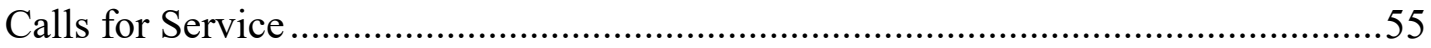

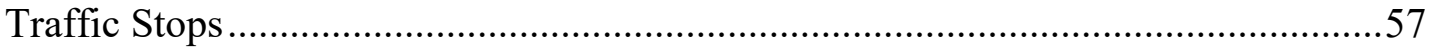

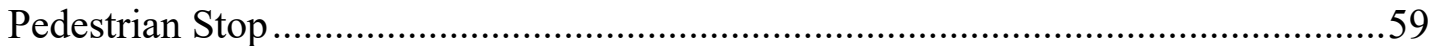

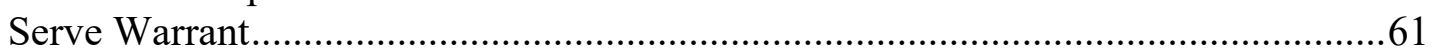

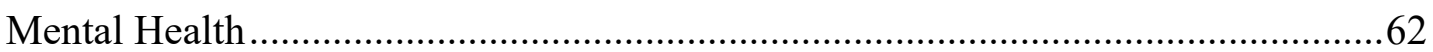

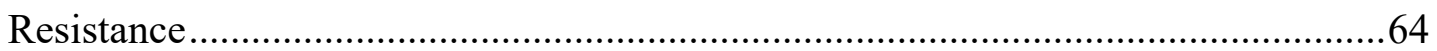

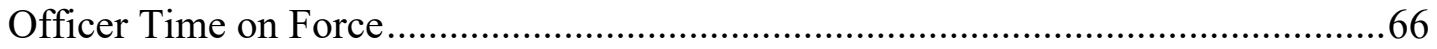

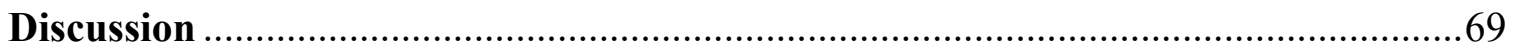

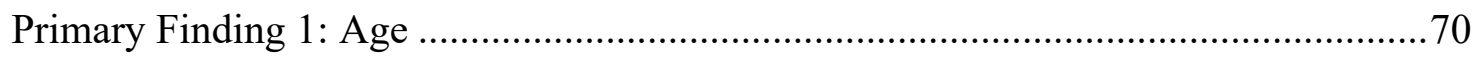

Primary Finding 2: Type of contact and public criticism .......................................... 71

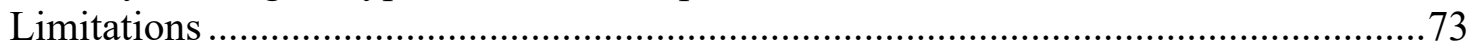

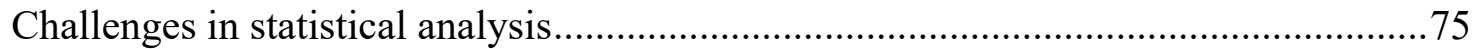

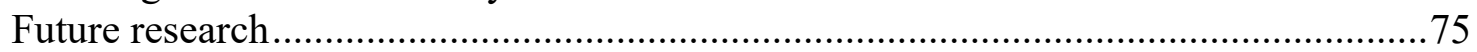

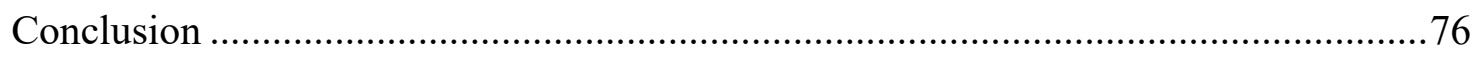

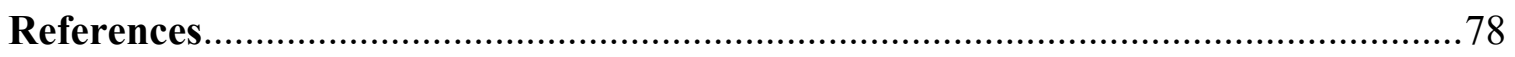

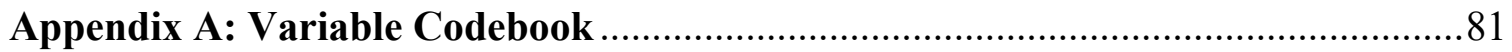

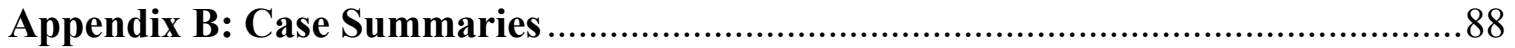




\section{List of Tables}

Table 1: US Victims of Police Deadly Shootings by Race Compared to Percentage of Total US Population

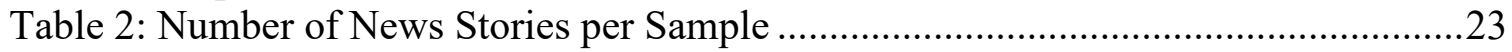

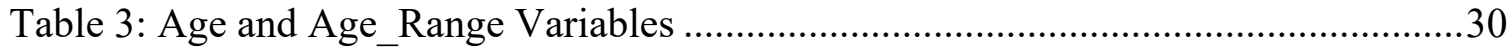

Table 4: Time_of_Day and Time_Period Variables.................................................... 31

Table 5: Location and Location_Condensed Variables...................................................32

Table 6: Frequencies for Type_of_Contact and Contact_Type_Condensed Variables ....35

Table 7: Call_Reason and Call_Reason_Condensed Variables .....................................36

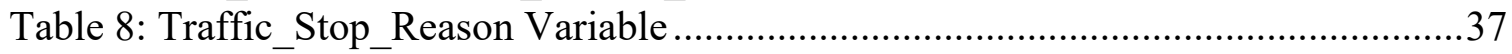

Table 9: Pedestrian_Stop_Reason Variable ............................................................. 38

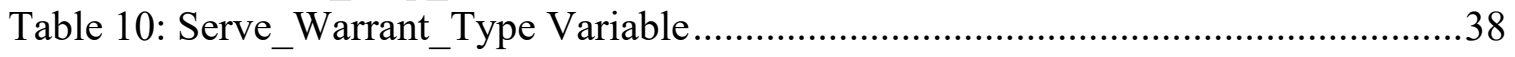

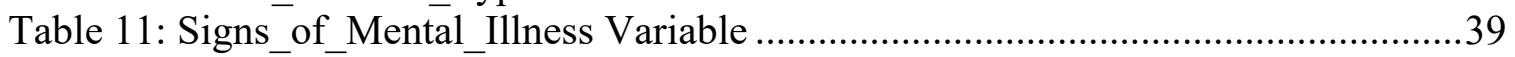

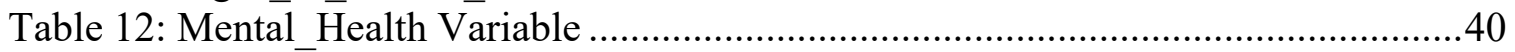

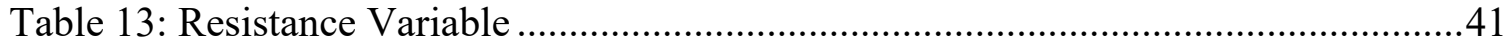

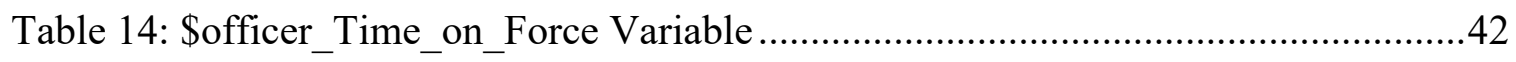

Table 15: Race and Age Independent Samples t-Test ..............................................44

Table 16: Reason for Contact * Race Crosstabulation: Subjects 45 and Older ................47

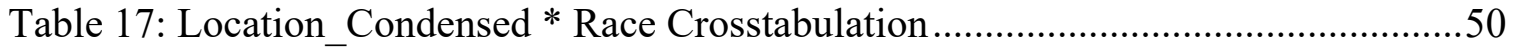

Table 18: Call Reasons Condensed * Race Crosstabulation ..........................................55

Table 19: Traffic_Stop_Reason * Race Crosstabulation...............................................57

Table 20: Pedestrian_Stop_Reason * Race Crosstabulation ........................................59

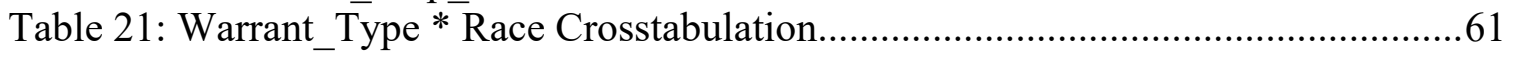

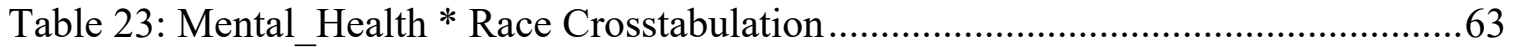

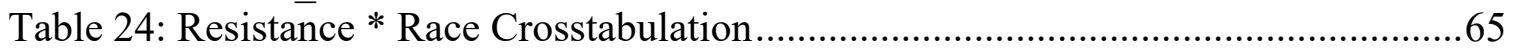

Table 25: \$officer_Time_on_Force * Race Crosstabulation..........................................67 


\section{List of Figures}

Figure 1: Process Model for Content Analysis..........................................................24

Figure 2: Age Distribution.................................................................................... 43

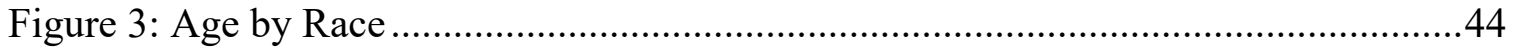

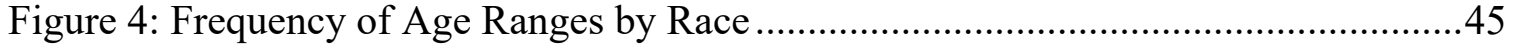

Figure 5: Frequency of Incidents by Time of Day ....................................................48

Figure 6: Time Period of Incidents by Race ............................................................... 49

Figure 7: Frequencies of Type of Contact by Race ........................................................52 


\section{Introduction: Public Criticism of Police Use of Force}

For as long as police have existed in democratic societies, their use of force has been accepted as a necessary part of effective policing (Alpert \& Dunham, 2004). In 19th century America, police were subject to little if any oversight. Police use of force was common and civilian disrespect for and distrust of police was high. This remained true in the United States until the middle of the 20th century, when the social movements of the civil rights era forced police departments to accept some level of external controls (Alpert \& Dunham, 2004).

Since the 1960s and 70s, police have been under increasing scrutiny over their practices, including use of force. This increased focus has led to a wide body of research into modern day police practices. Today, policing in America is a source of deep racial and political division. The Pew Research Center has found that $74 \%$ of white Americans view the police favorably compared to $30 \%$ of black Americans. Among Republicans, $86 \%$ view police favorably, while $57 \%$ of Democrats are similarly inclined (Fingerhut, 2017).

\section{Recent Citizen Complaints and Activism}

In the summer of 2014, the city of Ferguson, MO devolved into days of protests and riots over the shooting of Michael Brown, a young black man killed after an officer stopped him for jaywalking. Conflicting reports of what happened that afternoon added to the chaos as members of the community took to the streets in protest. The social movement of Black Lives Matter, created just one year prior in the wake of the acquittal of George Zimmerman in the murder of a young black teenager, Trayvon Martin (Matter, 
n.d.), soon became the predominant voice of criticism of police use of deadly force against people of color.

Since Ferguson, public outcry over what is seen as racially biased police use of force has exploded. In response to this criticism, a Blue Lives Matter movement has emerged to counter the message of Black Lives Matter. Activists on both sides use stories to support their respective positions on police and police practices. This has resulted in the use of extreme examples to characterize the issue of police use of force in communities of color. A common theme in activism critical of police is a comparison of how police treat violent white criminals, such as a mass shooter, with their treatment of black people suspected of petty crime. In these comparisons, a deadly police response is used against the black suspect, while the white suspect is peacefully arrested. Even worse, these comparisons sometimes include black individuals who are killed when they were not doing anything illegal at all.

Individual activists and activist groups who are active on social media often share stories that highlight these differences. Shaun King, founder of Real Justice and columnist for the Intercept, is one such activist. He is followed by nearly 2 million users on Facebook and has 1.11 million followers on Twitter. He recently shared a video on Facebook with the headline "Police fires shots at car driven by unarmed, non-violent Black woman". In the description of the video, he said this:

"Let me explain what you are seeing here because it's CRAZY. Police followed this car in New Haven, CT claiming it looked like a car involved in an armed robbery. The officer gets out, freaks all the way out for no reason at all, then fires a dozen shots at the car. He starts running away, convinced that the woman is shooting back at him. 
What he heard were his own bullets ricocheting off of the car. He shoots her in the face, but she has survived. She was unarmed. Her friend driving was unarmed.

Now take a moment and think about how white MASS SHOOTERS who are armed, sometimes with arsenals big enough for a small army, are never treated like this [emphasis added]." (King, 2019)

King's post was viewed 134,000 times and shared 5,687 times within 5 days of his posting. This is an example of the tone and message of many activists and activist groups concerned about racially biased policing and police use of force.

\section{Impact of Modern Policing Issues}

These polarizing messages directly threaten police legitimacy through compelling narratives about police misuse of deadly force in minority communities. When communities believe police are not treating them fairly, police legitimacy suffers (Tyler \& Huo, 2002; Tyler \& Wakslak, 2004). The belief there is disproportionate use of deadly force in minority communities may be accurate. In two studies that have analyzed a unique national data set on deadly police shootings developed by the Washington Post, both research teams found a racial disparity in the number of people killed by police. They found the rate for fatal shootings of black subjects ${ }^{1}$ is more than twice as high as the rate for white subjects (Nix, Campbell, Byers, \& Alpert, 2017; Shane, Lawton, \& Swenson, 2017).

\footnotetext{
${ }^{1}$ We use the term "subject" throughout this thesis to represent the individual who is killed by police. While these individuals are technically victims of deadly force, "victim" is a loaded term that carries an implication of innocence. Some individuals in the data set were actively shooting at officers or were otherwise an imminent threat to others. Labeling them a victim in this context places particular meaning on the situation that does not fit the context. Conversely, not all individuals killed by police are suspects of a crime, so using the term "suspect" is also an inaccurate reflection of the situation. A more neutral term of "subject" was chosen instead in an effort to remain objective and consistent when discussing the stories and situations of the individuals within this study.
} 
The general perception from the black community and their allies is that blacks are more likely to be treated unfairly by police and the criminal justice system. The Pew Research Center found that $84 \%$ of blacks believe the police treats blacks less fairly than whites, and $87 \%$ believe the criminal justice system treats them less fairly than whites (Brown, 2019). Between lived and vicarious experiences, as well as social media activism like that of King, it is unsurprising the black community would believe they are more likely to be unjustifiably shot during less serious police contact situations than white people. King's statements, and others like it, suggest the circumstances surrounding black shootings may differ from white shootings, in particular they may involve "less serious" antecedent and contextual factors. Given the political stakes, and the threat to police legitimacy, this is an important assumption to test and is the focus of this thesis. This thesis does not take a legal analysis of whether any shooting was justifiable, but instead examines whether there are important contextual and situational differences between the shootings of black and white suspects.

\section{Research Question}

This exploratory study seeks to answer the following research question:

Question 1: Are the situational factors in deadly police shootings different between black and white subjects?

In order to answer this question, multiple variables are constructed to quantify particular aspects of the police-citizen contact situation. Every police-citizen contact situation begins with an instigating event. These events set the stage for the rest of the interaction, including decisions to use force and what kind of force to use. Some 
interactions may begin with a call for service, others with a traffic stop. The reasons for calls or stops may explain why deadly force is used. Other considerations like the subject's mental health status, or what kind of resistance officers face may also explain the disparity in use of deadly force.

If situational differences are found between white and black subjects, it may indicate police respond differently to white and black subjects under these different situations. It could also indicate a differential frequency of criminal involvement in these situations among white and black subjects. If no differences are found, it would suggest that the situational factors alone are not sufficient to account for the disparity in use of deadly force. Using statistical evidence to examine what may be happening in deadly force situations will give us a deeper understanding of these relatively rare occurrences. This understanding may provide new insight into use of force policy, training, and legal discussions. 


\section{Review of the Literature}

\section{Theory Applicable to Use of Force}

In examining police use of force, there are several types of theories that can be applied to the research. These theories may focus on organizational factors of the police departments themselves, psychological characteristics of the individual officers, or sociological factors of the situations and subjects where police use force (Worden, 2015). Biased use of force is typically studied from a psychological or sociological perspective, with a focus on how implicit biases of the officer and/or the situational context impact his or her decision-making process during encounters with subjects (Bolger, 2015; Correll et al., 2007; Kahn, Steele, McMahon, \& Stewart, 2017; Terrill \& Reisig, 2003).

One sociological theory regarding use of force is the Authority Maintenance Theory (Alpert \& Dunham, 2004). Under this theory, police expect a level of deference from any civilian they encounter. If the person displays a lack of deference, or is disrespectful, the officer may respond with mild force. If the lack of deference includes some degree of resistance, then the force employed will increase. Under this theory, use of force becomes a process that evolves during an encounter, and can be used to explain high levels of force used against a subject who is not necessarily resisting in a manner that appears to warrant such force. For example, a series of disrespectful comments or looks may result in more severe force than a single disrespectful action. It is also expected that some level of disrespect may exist in the interaction when the civilian believes they are being unfairly targeted by the officer (Alpert \& Dunham, 2004), which is likely to be relevant within a distrustful minority community. The type of contact a 
subject experiences in a police-citizen encounter may influence their acceptance of the officer's decisions and commands and we may find more resistance following certain types of contact. Certain types of contact and the resulting resistance may also implicate public response to the outcome of a use of force situation (Tyler \& Wakslak, 2004).

The theory of social conditioning and illusory correlation provides a psychological perspective. According to this theory, continued exposure to differential levels of crime effect perceptions of race and criminality (Smith \& Alpert, 2007). According to this theory, over time police officers develop beliefs about racial groups based on the negative interactions they have. In practice, this means a police officer that spends a few years patrolling a predominately black, economically disadvantaged, high crime neighborhood, will begin to associate being black, with being poor and a criminal. This belief impacts all interactions with African Americans while on the job and can carry over off the job as well.

If viewed within the context of a situation where a police officer is expecting deference from an individual, and their perception of the individual is influenced by racial stereotypes, how they respond to that individual's lack of deference may be fundamentally different between white and black subjects. In other words, the degree of deference a police officer expects from a black subject, rather than a white subject, may be influenced by social conditioning. Further, it is possible that certain types of contact may change how both officers and subjects perceive and respond to the encounter which could have implications for use of force. 
Both the Authority Maintenance Theory and Social Conditioning and Illusory Correlation Theory may be relevant in racially biased use of force incidents. This thesis will consider both theories through the development of an original data set that includes a variety of situational variables and compares these situations between racial groups. These situational variables include the type of contact (i.e. calls for service or stops), officer time on the force, and resistance and the method of resisting. Other potentially relevant variables include the time of day, location, age, and mental health status of the subjects.

\section{Police Decision Making Research}

There has been substantial research in recent decades on police officer decision making regarding use of force. This research ranges from broad questions regarding decision making (Bolger, 2015; Friedrich, 1980; Terrill \& Mastrofski, 2002) to very specific decision to shoot experimental studies (Correll, J., Hudson, S. M., Guillermo, S., and Ma, 2014; Correll et al., 2007; Kahn \& Davies, 2017; Kenworthy, Barden, Diamond, \& del Carmen, 2011; Sim, Correll, \& Sadler, 2013) These studies have isolated some officer characteristics that impact use of force decisions, including biological or psychological factors related to fear, stress, and fatigue, as well as experience and training (Akinola \& Mendes, 2012; James, James, \& Vila, 2018; Nieuwenhuys, Oudejans, \& Savelsbergh, 2012).

Decision to shoot experiments have also identified characteristics of the subject and elements of the encounter that factor into the decision to use force (Bolger, 2015). Potentially relevant subject characteristics include mental health status, substance abuse, 
armed or threatening behavior and resistance, and physical characteristics such as clothing or race of the subject (Alpert, 2015; R. R. Johnson, 2011; Kahn \& Davies, 2017; Morabito \& Socia, 2015; Ruiz \& Miller, 2004; Terrill \& Mastrofski, 2002; Watson, Corrigan, \& Ottati, 2003; Watson, Swartz, Bohrman, Kriegel, \& Draine, 2014). Environmental elements that have been found to contribute to the decision to use force, include neighborhood characteristics and the time of day (Kahn \& Davies, 2017; Terrill \& Reisig, 2003)

\section{Decision to Shoot Experiments}

Decision to shoot studies are one of the few areas where experimental design has been employed to study police decision making. These experiments use a first person shooting task (FPST) to test the accuracy shoot-don't shoot decision making of both sworn officers as well as college student participants. In these tests, typically a photo of a suspect is presented on a computer screen, and the participant must select to shoot or not shoot the target. Each suspect is presented holding a weapon or a neutral object and the participant must make a shooting choice within a fraction of a second (Correll, J., Hudson, S. M., Guillermo, S., and Ma, 2014).

Officer fatigue, as it relates to time of day and during which shift an officer works, has been found to reduce accuracy in FPST studies. When officers are tired, they take more time to make decisions and are more likely to incorrectly identify armed or threatening subjects (James et al., 2018). This thesis will consider the time of day of each incident to determine if deadly shootings occur during particular times that may implicate officer fatigue. 
In news coverage of police deadly shootings, officers sometimes report having no choice but to shoot as they feared for their safety and that of other officers or civilians. This fear can impact decision making, either increasing or decreasing the error rate in decisions to shoot. Some fear heightens senses and increases the ability of an officer to correctly identify an armed target, but too much fear leads to an increase in error and incorrectly identifying the armed target (Correll, J., Hudson, S. M., Guillermo, S., and Ma, 2014). It may be that certain types of contact with subjects include more uncertainty, particularly in situations where little information is known to the officer prior to contact with the subject. This is most likely to be the case during traffic or pedestrian stops compared to calls for service, where dispatch information can reduce uncertainty (Johnson, Cesario, \& Pleskac, 2018). Data trends in the type of contact explored in this thesis may relate to uncertainty and inaccurate decisions to shoot.

\section{Racial Bias in Police Decision Making Research}

Systemic racial bias in the criminal justice system has also been a topic of considerable research. In regard to policing, implicit racial bias and its effect on policing outcomes, such as arrest rates, remains a topic of interest for researchers and the public alike. Increasingly, the relationship between use of force and race has been the subject of research efforts (Charbonneau, Spencer, \& Glaser, 2017; Correll et al., 2007; James, Vila, \& Daratha, 2013; Kahn et al., 2017). Evidence from FPST does point toward there being an effect of implicit, subconscious bias against non-white subjects. 


\section{Racial Bias in Decision to Shoot Experiments}

A review of studies found officers are quicker to make the decision to shoot a black target than a white target and this appears to be related to issues of stereotype congruent cognitive processes. When the stereotypes are congruent, such as an armed black man, the correct decision can be reached quickly. When the stereotype is incongruent, such as an armed white man, it takes a fraction of a second longer to make the decision. When racial bias affects white targets, it acts as a protective factor in reducing the number of shootings, by slowing the decision making process and resulting in more errors to not shoot an armed white target. An opposite effect of racial bias happens with black targets in these studies, with greater error to shoot an unarmed black target (Correll, J., Hudson, S. M., Guillermo, S., and Ma, 2014).

Several factors influence the degree to which an officer might express racial bias in their decision-making processes. One factor relates to training and experience. Officers are found to be more accurate in these FPST tests than student participants. This suggests the training an officer undergoes helps them to make better decisions regardless of any biases they have (Correll, J., Hudson, S. M., Guillermo, S., and Ma, 2014). Accurate dispatch information also assists officers in making accurate, less biased, decisions in the field (Johnson, Cesario, \& Pleskac, 2018). This later finding may have implications for differences in types of contact, where dispatch information in calls for service provide protective factors against bias. In addition, it is possible that younger, less experienced officers may be more prone to shoot black subjects than white subjects, with more 
experienced officers making the decision to shoot more equally between groups. This will be explored within the analysis using officer time on the force to compare groups.

\section{Terry Stops and Stop and Frisk}

Pedestrian stops are one way a police-citizen interaction can begin. These stops may occur during routine patrols, when an officer observes something suspicious while conducting unrelated work, or as a response to a call for service. Racial differences in use of force during pedestrian stops indicate a $27 \%$ increase in odds that a black person will experience force during the stop than a white person (Kramer \& Remster, 2018). Additionally, use of weapon force during a stop is slightly more likely for black persons compared to white persons during these stops (Morrow, White, \& Fradella, 2017). The differences in use of force with white and black subjects during pedestrian stops may explain some of the variability in police use of deadly force between these two groups.

\section{Traffic Stops and Searches}

In a report from the Bureau of Justice Statistics on involuntary contact with the police, $13 \%$ of black respondents reported being pulled over by the police compared to $10 \%$ of whites. Black drivers were ticketed or searched during these stops more frequently than whites (Langton \& Durose, 2013). More stops, and more searches, for black persons is reflected elsewhere in the literature, even when accounting for other relevant variables such as community demographics (Rojek, Rosenfeld, \& Decker, 2012). As with pedestrian stops, racial differences in who is contacted for a traffic stop may be reflected in the situational differences leading up to deadly shootings of black and white subjects. 


\section{Resistance During Contact}

Subject behaviors and demeanor also impact officer decisions to use force.

Resistance to officer demands or actions increases the general use of force by officers. However, demeanor does not when it is separated from resistance (Terrill \& Mastrofski, 2002). Some forms of negative demeanor may be related to resistance, such as when a subject argues with officers about being detained, however, by itself without some form of active resistance such issues of behavior were not enough to bring use of force against the subject (Terrill \& Mastrofski, 2002). Recall the importance of resistance in the theoretical explanations on use of force. Whether the subject resisted and what type or form that resistance took will be explored in the analysis.

\section{Subject Clothing, Race, and Neighborhood}

Clothing of suspects also plays a role in threat assessment of targets. In FPST tests, participants viewed black subjects as less threatening when paired with a good neighborhood prompt and were dressed in a business suit. By comparison, clothing and neighborhood had no impact on the threat assessment of white subjects by participants in the study (Kahn \& Davies, 2017). This supports earlier work that indicates police use higher levels of force in neighborhoods judged to be more dangerous, with high crime and concentrated disadvantage (Terrill \& Reisig, 2003). We do not have data on neighborhood level characteristics and will instead consider micro level locations such as if an incident occurred on the street or at a house. If differences are found in the microlocations of incidents of black and white victims, it may indicate some support for 
previous research that considers location-based context an important determinate for disparate treatment of black and white targets.

\section{Police Use of Force and the Mentally Ill}

Approximately 7 percent of police contacts in jurisdictions over 100,000 population are believed to be with persons suffering from a mental illness (Deane, Steadman, Borum, Veysey, \& Morrissey, 1999). It is certainly possible this number has changed since Deane et al explored the issue of mental health and policing, however, their research and that of others demonstrates one significant challenge of research in this area - officers are asked to label persons as mentally ill without an actual clinical diagnosis (Alpert, 2015). To some degree, this may be irrelevant for the purposes of understanding use of force against the mentally ill.

It may be that the perception of police about the mentally ill, their dangerousness specifically, is the critical piece that determines what will occurring during these police contacts. Stigma about mental illness leads to a perception that the mentally ill are dangerous. As many as $43 \%$ of officers in Pennsylvania report agreeing to the statement that persons with mental illness are dangerous (Ruiz \& Miller, 2004). This is in spite of data that shows the risk of officer injury is reduced when dealing with persons perceived to be suffering from mental illness. Only in situations where the perception of mental illness was paired with perceived substance abuse did the likelihood of officer injury increase. (Morabito \& Socia, 2015).

Despite perceptions of increased dangerousness of the mentally ill, police are more willing to help persons they believe are suffering from a mental health illness such 
as schizophrenia (Watson et al., 2003). These perceptions may also be important to the type of call received by police. Calls for service where the subject is female and compliant were perceived to be easier, and the police made greater attempts to get the person help through public service agencies. However, when the call involved a male subject who was not cooperative, was perceived to have mental health and substance abuse issues, and was exhibiting poor hygiene, that call was viewed as more dangerous and difficult. These perceptions have direct implications for how police make decisions, including use of force decisions, when responding to calls for service (Watson et al., 2014). A broader "impairment" designation is used in some research, which combines both mental illness and substance use into a single category. The results of such studies reflect the findings elsewhere that an impaired individual is perceived as being more challenging to work with, but is also no more likely to injure an officer during the interaction (Kaminski, Digiovanni, \& Downs, 2004).

Use of force against mentally ill persons is highly dependent on the presence of other personal factors, including resistance, demeanor, and armed status of the individual. Additionally, the co-occurrence of substance abuse with mental illness further complicates the relationship and adds an additional element that police must factor in to their decision making. When these other factors are controlled for, a person with mental illness is not more likely to have force used against them (Terrill \& Mastrofski, 2002). However, in the field these factors cannot be separated, and if the perception of mentally ill persons is they are dangerous, it is likely force may be used to resolve the situation. 
Johnson (2011) found that when force is measured on a continuum, there is no increase in force used against mentally ill persons. However, when only serious force is considered, subjects with perceived mental illness had force used 3 times as often as those without mental illness. Johnson (2011) also found the additional factors of substance abuse, resistance, etc. identified elsewhere in the literature had high collinearity with mental illness. His findings suggest it is possible that the increase in use of force is because mentally unstable persons are more likely to resist or be armed (R. R. Johnson, 2011). A non-diagnostic measure of mental illness will be used in the analysis to determine if there are situational differences between white and black subjects with signs of mental illness.

\section{Research Challenges in Examining Deadly Force}

Most of the use of force literature discussed here has focused on a wide range of force incidents, of which deadly force is a very small fraction. In part because of this relatively small number of incidents, as well as incomplete national data, use of deadly force has not been extensively studied. Use of force studies generally look at a single jurisdiction, which offers an in-depth study of how officers use all forms of force but may provide few if any incidents of deadly force. Such studies are able to identify differences in lower levels of use of force between groups of people, but not differences in deadly force. Without a substantial number of deadly force incidents, a study on a single jurisdiction cannot identify differences between groups of people and use of deadly force. For this reason, relying on national level data is vital in any research on deadly force. 
When deadly force has been investigated, it has often been limited to those laboratory studies on decisions to shoot and implicit bias. Prior to 2015, national level data on deadly force was limited to official data sources. Research that relied on such data faced several problems. The official data is incomplete because local police departments are not required to report use of force, including deadly force, to any official government body. This results in only a portion of deadly force incidents being reported. When data is reported, there may be differences between jurisdictions on what is reported. For example, a department may only report police use of a firearm when a civilian is injured or killed, but not report when the officer misses the target and no one is injured (Klinger, 2012). Additionally, when data is made available, it is difficult to compare one jurisdiction to another because of a lack of standardized reporting of use of force (Alpert \& Dunham, 2004).

In the wake of recent high-profile deadly force incidents, such as the shooting of Michael Brown in Ferguson, MO, journalists became aware of this problem with official data. In an effort to generate a more complete look at deadly force across the country, they began crowdsourcing data on deadly police shootings beginning in 2015 . The Guardian and Washington Post newspapers both developed data sets of recent incidents where a civilian died from injuries inflicted by police use of force. Their crowdsourcing method collected basic information about each known incident of deadly force. Relying on tips from the public as well as local reporting, they generated a data set with a series of basic factual variables. While not without limitations, such data provides researchers with a picture of the issue at a national level that is not available through official sources. 
Based on the data available from the Washington Post, on average, close to 1,000 incidents of fatal police use of deadly force have occurred each year since 2015. This number is roughly twice as high as official data from the government (Tate et al., 2016). As mentioned in the introduction, two studies have been conducted using some of the Washington Post data. Findings from 2015 data suggest that black subjects are disproportionately killed compared to white subjects. These shootings also occur more often against black subjects who are not attacking the police or threatening other civilians and who are unarmed, than they do among white subjects under similar situations (Nix et al., 2017; Shane et al., 2017).

While the Washington Post data provides some very good information, potentially relevant specifics are left out that may be important to use of deadly force. In particular, details on the type of contact and what kind of resistance individuals engage in prior to being killed by police are missing from the Washington Post data. Also missing are officer level characteristics, such as time on the force, and the location of the incident. This thesis will utilize the data from the Washington Post as the starting point for the research. Original data collected from a content analysis of news reports will provide greater depth in understanding the situational factors present in a sample of these incidents than previous research in this area has been able to identify. The variables created during this process include the time of day and location of the incident, type of contact, reason for each type of contact, the subject's mental health status, the kind of resistance officers faced, and the officer's experienced measured as their time on the force. This new data will explore the research question to determine which, if any, of 
these situational factors are related to the observed disparity in use of deadly force between white and black subjects. 


\section{Methodology}

This exploratory study seeks to answer the following research question:

Question 1: Are there different situational factors between incidents of deadly police shootings of white and black subjects?

\section{Sampling Procedure}

Drawing on the Washington Post data (Post, 2017) of deadly police shootings around the country from 2015 through 2017, a stratified random sample was created. Within this data set, all variables were string variables, except for "year", "date", and "age" which were numeric. In order to generate the stratified random sample, the variable "race" was recoded into a nominal numeric variable with codes $0=$ white, $1=$ Black, 2=Hispanic, $3=$ Native American, 4=Asian, 5=Other. From the master data set, two lists were created, one for all white subjects for all three years, and another for all black subjects for all three years. Two samples were generated through the simple random sample procedure in IBM SPSS, creating a sample of $n=50$ white and $n=50$ black subjects. These two $n=50$ samples were combined into a single data set and utilized for the content analysis portion of this thesis.

The total number of deadly shootings during this three year span was $\mathrm{N}=2945$. Of this number, $5.9 \%(n=174)$ were missing data on race, so were excluded from consideration in the generation of the stratified sample. Of the remaining $\mathrm{N}=2771,51.2 \%$ were white $(n=1420), 25.8 \%$ were black $(n=716), 18.4 \%$ were Hispanic $(n=511), 1.7 \%$ were Native American $(n=47), 1.6 \%$ were Asian $(n=45)$, and 1.2\% were some other race or mixed race $(\mathrm{n}=32)$. 
White subjects were included in the stratified sample because they make up a majority of the victims of police deadly shootings and are underrepresented in comparison to their percentage of the total US population. Black subjects were also included as the second largest segment of victims, and are over represented compared to their percentage of the US population. The other racial groups were excluded for one of two reasons. Hispanics were excluded because their percentage of shooting victims is very similar to their percentage of the total US population. The remaining groups were excluded because their $n$ was too small (Native Americans, Asians, and Other). See table 1 below for a detailed comparison.

Table 1: US Victims of Police Deadly Shootings by Race Compared to Percentage of Total US Population

\begin{tabular}{llrrr} 
& $f$ & $\%$ & $\begin{array}{r}\% \text { US } \\
\text { Population* }\end{array}$ \\
\hline Race & White & 1420 & $51.2 \%$ & $60.7 \%$ \\
& Black & 716 & $25.8 \%$ & $13.4 \%$ \\
& Hispanic & 511 & $18.4 \%$ & $18.1 \%$ \\
Native American & 47 & $1.7 \%$ & $1.3 \%$ \\
Asian & 45 & $1.6 \%$ & $5.8 \%$ \\
Other & 32 & $1.2 \%$ & N/A \\
\hline & Total & 2771 & $100 \%$ &
\end{tabular}

* US Population Estimate 2017: 325,719,178

\section{Content Analysis: Content Acquisition}

The Washington Post data set was created as an attempt to count every police deadly shooting in the US. In this data set are several relevant variables, including the city and state where the shooting occurred, basic demographics of the subject, if they were armed at the time of the shooting and what the weapon was, if they were fleeing or not, if the officer(s) involved were wearing body cameras, and if there were signs of mental illness present in the victim. While this data provides some contextual information 
to each situation, it is limited in detail. The content analysis expands on this data to provide greater detail about the situations that led to police using deadly force on each subject. These details may shed light on why some racial groups are overrepresented or underrepresented in deadly police encounters.

The content analysis was conducted using Atlas.ti. News stories of each of the incidents were found using a basic Google search. The typical search term used was “[FIRST and LAST NAME] police shooting”. Nearly all searches produced results with the correct victim and multiple news stories on the first results page from local news outlets, both television stations and local/regional newspapers. In some instances, the search term did not produce correct results, such as when the victim had a very common name or a last name that might also be a first name, like Daniel Davis or William Gary. Occasionally police officers with those names or similar names might show up regarding an officer being killed or being involved in an unrelated shooting. When the initial search did not generate stories about the specific case, the date and/or location of the incident were added to the search term. This new search term would generate the correct news stories.

In total, 209 news stories were identified for the white subjects and 153 news stories were identified for the black subjects in the sample. Table 2 shows the frequency distribution of news stories between each group. Each news story was skimmed to verify it was covering the correct incident, and the story was converted to a PDF file and loaded into Atlas.ti for analysis. These documents were placed into document groups for each case, for later detailed analysis. During coding of these documents, some documents were 
removed if there was an error in how the pdf was generated, making it unreadable. ${ }^{2}$ When this occurred, the documents were replaced only when there were not at least three other documents already in the document group for that case. The coding process of the content analysis involved three phases.

Table 2: Number of News Stories per Sample

\begin{tabular}{l|c|cc|rr|c}
\hline \multicolumn{2}{c}{} & \multicolumn{2}{c}{ White Subjects } & \multicolumn{2}{c}{ Black Subjects } & \multicolumn{2}{c}{ Total } \\
\multicolumn{2}{c}{} & \multicolumn{1}{c}{$f$} & $\%$ & $f$ & $\%$ & $f$ \\
\hline \# of News & 1 & 1 & 2 & 1 & 2 & 2 \\
Stories & 2 & 3 & 6 & 8 & 16 & 11 \\
& 3 & 12 & 24 & 32 & 64 & 44 \\
& 4 & 14 & 28 & 8 & 16 & 22 \\
& 5 & 13 & 26 & 1 & 2 & 14 \\
& 6 & 5 & 10 & 0 & & 5 \\
& 7 & 1 & 2 & 0 & & 1 \\
& 8 & 1 & 2 & 0 & & 1 \\
\hline Total & & 50 & 100 & 50 & 100 & 100
\end{tabular}

\section{Terminology of Content Analysis Research}

During a content analysis, manifest coding is typically the first step in analyzing written work. Manifest codes are select words, phrases, or full quotes of text of what was literally said in the text documents. Manifest codes objectively mean what the text says, such as when coding time of day. The second step in a content analysis is generally to provide a subjective meaning to manifest codes. This is called latent coding and the product is a latent code. Latent codes represent the underlying meaning of a manifest code or a series of related manifest codes. Latent codes can also be used to count

\footnotetext{
${ }^{2}$ In a few instances a new Google search was performed and an additional article or two was added to the document. In at least one case the process of creating a PDF from the news story through the "export pdf" function on a Mac generated a PDF of a different news story. Using the "print, save as PDF" function instead allowed for the correct story to be turned into a PDF for use in Atlas.ti. In the vast majority of cases, there were no issues with PDF files.
} 
instances of themes or concepts. The next step in a content analysis might involve, as it does in this research, to select latent codes to be converted into single discrete variables. All latent time codes, until now associated with a single case, would be combined into a variable with a data field of "time of day" for each case. See Figure 1 for a visual depiction of this process.

Figure 1: Process Model for Content Analysis

\section{"...The police were called to the scene of a robbery at 4:51 pm yesterday..."}

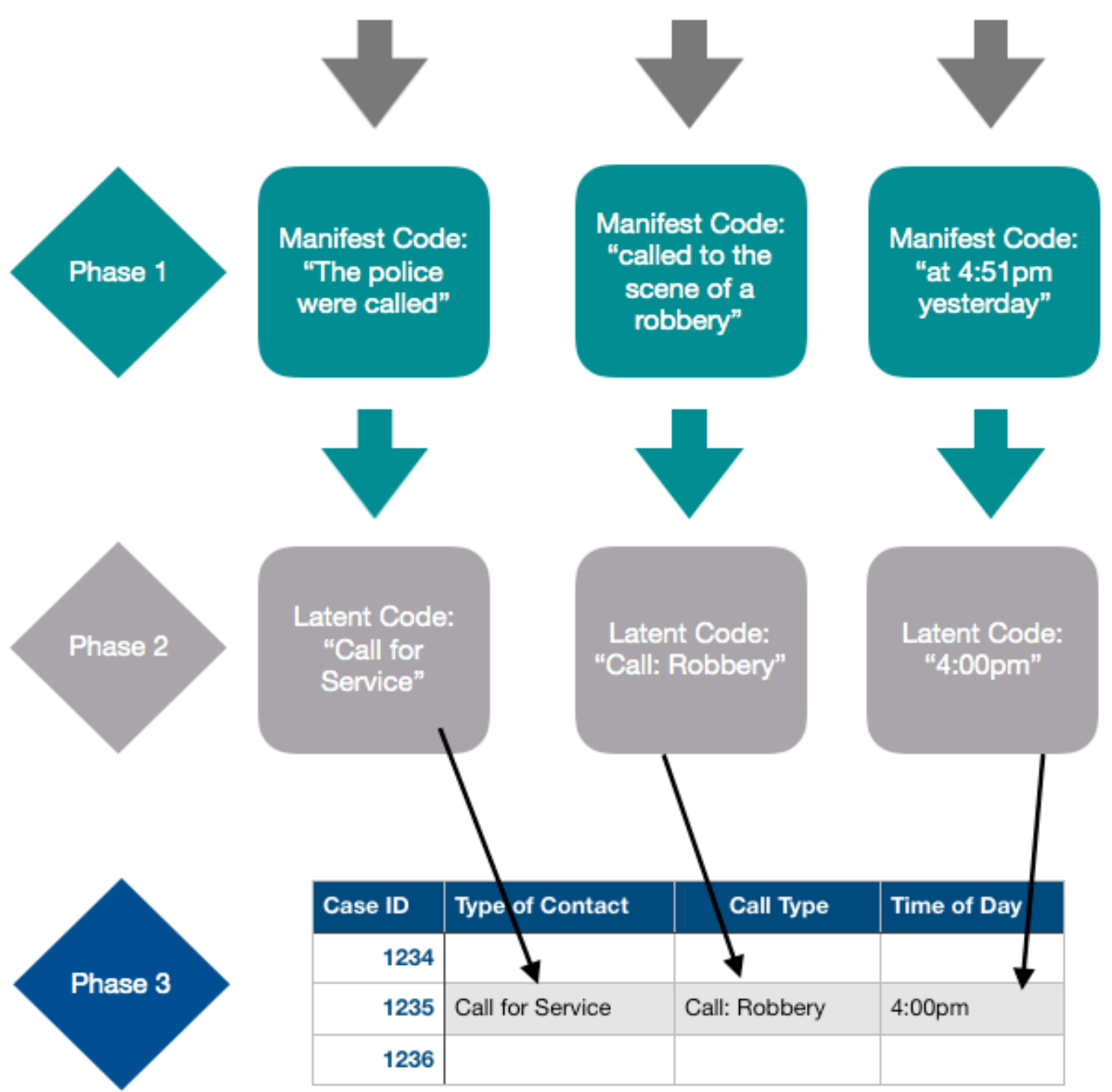




\section{Content Analysis Process}

\section{Phase One: Exploratory analysis using manifest coding}

The white subjects were the first to go through the coding process in Atlas.ti. Using the command "code in vivo", short phrases and occasional long quotes were selected to represent situationally relevant information. These are the manifest codes for the sample. Information relevant to the construction of future variables, based on previous research and the theories that guide this thesis were identified in phase one. Many other facts that seemed important to the event were manifest coded, including the use of police negotiators, threats to the officers or innocent bystanders, or the location of the event. Because the process of manifest coding results in a unique code for each selected word, phrase, or quote, this process produced 605 unique codes within the white subjects alone. Many of these manifest codes actually mean the same thing as another code. This is resolved during phase two with latent coding.

\section{Phase Two: Latent coding}

This second round of coding was performed on paper, with a manual review of all the manifest codes generated in the white subjects. Each case in the data set had multiple articles that had been read to generate data points though manifest codes. These codes were grouped by case and sorted by hand one case at a time. Countable variables were identified and listed for each case. These included distinct traits, like the location of the shooting, which might be a house, apartment, street, or parking lot. Each case received a latent code specific to the location description that had been manifest coded during phase one. 
Themes across cases were identified and manifest codes were condensed into latent codes. For example, some cases involved distinct events such as a standoff that required police negotiators, before the situation devolved into a shootout with police. Because the manifest codes are what was literally said in each document, there were many instances of different manifest codes that all meant the same thing. "A standoff began and ended when negotiations failed and a shootout occurred..." means the same thing as "Negotiators tried to end the standoff, but it devolved into a shootout..." Each of these quotes would be a unique manifest code. Latent coding of these details produced shorter latent codes such as "standoff", "negotiation", and "shootout".

The latent coding process for the white subjects was used to develop a coherent, universal code scheme which would become the basis of all the quantitative variables that were created for the quantitative analysis. Recall after phase one there were 605 manifest codes derived from the news stories about white subjects. After latent coding, this list was reduced to 185 latent codes and a codebook was generated for the white subjects.

Using the codebook from the white subjects, phases one and two could be completed simultaneously for the black sample. When relevant information was found in the news stories about the black subjects, phrases and quotes were either latent coded from the codebook, or new codes were added. These new codes were created following the coding schema already developed. For example, within the black sample, an officer was identified as being with the department for 24 years. In the white sample, no officers were identified with that many years on the job, so this became a new latent code in the codebook for the black sample. After coding the black sample, any codes within the 
codebook that were not utilized were removed from the black sample codebook, leaving a total of 182 latent codes. This results in slightly different codebooks for each sample.

\section{Phase Three: Creation of variables}

These latent codes would eventually be condensed further into discrete variables. Refer to Figure 1 for a visual representation of this process. Each codebook was exported into Microsoft Excel into its own worksheet divided by race. This produced a very large table, with 50 rows for each case of white or black subjects, and $180+$ columns for each latent code. Each latent code's column had a count for how many times that latent code appeared for each case. Each of these columns could be converted to a dummy variable. For example, in the column for latent code "Call for Service", each cell would have a "0" if that code doesn't apply to that case, or a " 1 " if there was one instance of that code within that case.

These codes were then condensed into single variables with multiple values, usually in string format. All the "l"s in the call for service column would be replaced with "Call for Service, and copied into a new column for the variable. In this case, that variable would be type_of_contact. Once all the different latent codes associated with the type of contact were added to this new variable for each case, that data was copied into SPSS and a new variable was added to the data set. Twenty new variables were created through this process. Not all are included in the analysis in the interest of brevity. The remaining columns within the excel spreadsheet could be combined into further variables in the future or retained as dummy variables. 


\section{Quantitative Methods}

The quantitative analysis uses some variables from the Washington Post data, although most of the analysis uses the variables generated in phase three of the content analysis. Variables provided by the Washington Post were primarily nominal, string data, and some were recoded into nominal, numeric data. Gender was recoded as dichotomous $0=$ male and $1=$ female. Race was recoded as $0=$ white, $1=$ black. The variable construction process is described in detail in the results section of this thesis and variables are listed in Appendix A.

The statistical analyses utilized are frequencies, percentages, crosstabulations, independent samples t-Test and Chi Square tests of independence. Limitations due to sample size and the nominal nature of the variables limits the statistical analysis to these tests. Whenever possible, Chi Square tests are used. The structure of the analysis begins with a general description of the variable, followed by chi square tests when appropriate. Additional context to these results is presented after the quantitative analysis. This is particularly useful to demonstrate differences in the situational factors when frequencies are too low for chi square tests.

The results section begins with a description of each variable and how it is constructed along with descriptive statistics or frequency tables. The second part is divided into sections by each variable and the quantitative and qualitative results are presented for each variable. The results for each variable are framed within the context of attempting to answer the research question. 


\section{Results}

\section{Content Analysis and Variable Construction}

Each of the variables described in this section are used in the quantitative analysis. The majority of them were created using codes developed through phases one and two of the content analysis. Recall that phase one involved selecting words, phrases, or quotes that seemed meaningful in addressing the research question. These selections became manifest codes, or what was said about each incident within the sample. During phase two, these manifest codes were subjectively interpreted and recoded into latent codes, which represent the underlying meaning of the manifest code. Approximately 180 latent codes were developed for each group (white and black subjects) within the sample. See Figure 1 on page 23 for a process diagram.

\section{Variable List: (See also Appendix A)}

\section{Race}

The variable race was created by researchers with the Washington Post during the creation of their data set and was originally a nominal string variable. It was recoded and utilized in this thesis as a dichotomous variable, $0=$ white, $1=$ black.

\section{Age and age_range}

The age variable was already present in the Washington Post data set and was not created through the content analysis. One person within the white sample was missing this data point. Content analysis data was used to supplement this missing value by finding the subject's age in a news story. Based on the frequency distribution of the variable and the relatively small counts for multiple ages, this variable was also recoded 
into a new variable age_range. Age_range used a common grouping scheme of 17 and under, 18-24, and then groups of ten beginning at 25 and ending at 64 , followed by a final group of 64 and older. Both variables are numeric scale variables. Table 3 provides descriptive statistics for these variables.

Table 3: Age and Age_Range Variables

Descriptive Statistics

\begin{tabular}{lrrcrr}
\hline & $\mathrm{N}$ & Min & Max & Mean & SD \\
\hline age & 100 & 17 & 77 & 36.31 & 12.973 \\
age_range & 100 & 1 & 7 & 3.70 & 1.345 \\
Valid N (listwise) & 100 & & & & \\
\hline
\end{tabular}

\section{Time_of_day and time_period}

The variables time_of_day and time_period were created during the content analysis. Time codes for each case are based on when the situation began, and not when the shooting occurred. It seemed relevant to know when the situation began for each case in an effort to determine if the situations that led to deadly shootings tend to occur at particular times during a 24-hour window. During phase one of the content analysis, all cases were manifest coded based on the time reported in news stories. During phase two these unique time codes were recoded into latent codes in one-hour periods using a 12hour format. For example, any situation that began between 2:00 pm and 2:59 pm was recoded as 2:00 pm. During phase three of the content analysis, the 12-hour format was recoded into 24-hour format and the time code for each case was added to the time of day variable. Four cases within the sample are missing time of day, leaving a total of 96 cases for analysis. 
Time_period is a new variable created from the time_of_day variable. Frequencies in each time value were four or less for 15 out of 23 time values. In order to generate larger frequencies based on logical groupings of time period, the variable time_of_day was recoded into an ordinal variable time_period using six groupings of four hours each. 6:00 am through 9:00 am was recoded $=1$ (Morning), 10:00 am through 1:00 $\mathrm{pm}=2$ (Mid-Day), 2:00 pm through 5:00 pm $=3$ (Afternoon), 6:00 pm through 9:00 $\mathrm{pm}=4$ (Evening), 10:00 pm through 1:00 am $=5$ (Night), and 2:00 am through 5:00 am =6 (Early Morning). Table 4 provides descriptive statistics for these two time variables.

Table 4: Time_of_Day and Time_Period Variables

Descriptive Statistics

\begin{tabular}{lrrcrr}
\hline & $\mathrm{N}$ & Min & Max & Mean & SD \\
\hline time_of_day & 96 & $1: 00$ & $24: 00$ & $13: 50$ & $7: 05$ \\
time_period & 96 & 1 & 6 & 3.85 & 1.529 \\
Valid N (listwise) & 96 & & & & \\
\hline
\end{tabular}

\section{Location and location_condensed}

Manifest codes of locations produced a substantial variety of places, as reporting was often highly specific. Subjects might be killed in a doorway, a driveway, or behind a dumpster in a parking lot. Some thematic element was needed to create a more manageable number of locations. During phase two these locations were latent coded into one of 17 locations. These 17 locations represent a general description of the location. For example, "house" encompasses single family homes, and their driveways, front, side or backyards. It does not include the sidewalk or street right in front of the house. Some latent code choices were based upon a subjective interpretation of danger. For example, an apartment is not the same as a house because the proximity to possible bystanders who might be injured in an altercation is different in high density housing compared to a 
neighborhood of single family residence. While a house and an apartment represent the private space of the subject, differences in features immediately surrounding the private space fundamentally change the context of the location. Therefore, apartment is its own latent code.

Phase 3 involved condensing each case's location code into a single location variable. However, with 17 values spread across 100 cases, frequency issues were a problem for any future analysis. To remedy this, location_condensed was created by combining values into four distinct categories: house, street, apartment, and other. Table 5 outlines the frequencies of each variable. The values included in each of the four categories of location_condensed are also provided in Table 5.

Table 5: Location and Location_Condensed Variables

Frequencies

\begin{tabular}{lrrr}
\hline location & $f$ & $\%$ & Cum\% \\
\hline House & 26 & 26.0 & 26.0 \\
Street & 34 & 34.0 & 60.0 \\
Apartment & 8 & 8.0 & 68.0 \\
Apt Common Area & 5 & 5.0 & 73.0 \\
Parking Lot & 5 & 5.0 & 78.0 \\
Wooded Area & 2 & 2.0 & 80.0 \\
Barn & 1 & 1.0 & 81.0 \\
RV/Trailer Park & 2 & 2.0 & 83.0 \\
Duplex & 1 & 1.0 & 84.0 \\
Hotel & 3 & 3.0 & 87.0 \\
Alley & 3 & 3.0 & 90.0 \\
Sidewalk & 2 & 2.0 & 92.0 \\
Public Area & 1 & 1.0 & 93.0 \\
Train & 1 & 1.0 & 94.0 \\
Highway & 3 & 3.0 & 97.0 \\
Car & 2 & 2.0 & 99.0 \\
Mall & 1 & 1.0 & 100.0 \\
\hline Total & 100 & 100.0 &
\end{tabular}

\begin{tabular}{lrrr}
\hline location_condensed & $f$ & $\%$ & Cum\% \\
\hline House (house) & 26 & 26.0 & 26.0 \\
$\begin{array}{l}\text { Street (street, alley, sidewalk, } \\
\text { highway, car) }\end{array}$ & 44 & 44.0 & 70.0 \\
$\begin{array}{l}\text { Apartment (apartment, apt } \\
\text { common area, duplex, }\end{array}$ & 16 & 16.0 & 86.0 \\
$\quad$ rv/trailer park( & & & \\
$\begin{array}{l}\text { Other (parking lot, public } \\
\text { area, train, hotel, mall, barn, }\end{array}$ & 14 & 14.0 & 100.0 \\
wooded area) & & & \\
\hline Total & 95 & 100.0 & \\
& & & \\
& & &
\end{tabular}




\section{Type_of_contact and contact_type_condensed}

The variable type_of_contact includes all the reasons the police-citizen contact occurred prior to a shooting. During the first two phases of coding, words and phrases were selected that indicated the type of contact. Phase two was particularly challenging with this variable. Some cases were complex and included multiple types of contact. For example, a case might include a manifest code "call about shots fired" while simultaneously a manifest code "a patrol officer heard gun shots". In cases like this, the latent code chosen to represent the contact type would depend on which type of contact would be most likely to lead to police-citizen interaction. This example was latent coded as a call for service. It seemed more likely an officer would locate the subject based on call information, rather than a visual search in the general direction of the gunshots. During phase three, the latent codes were transferred into the variable type_of_contact. This produced 10 types of contact.

Given low counts in eight of the contact types, as seen in Table 6, this variable was condensed to increase the frequencies for each type for purposes of statistical analysis. Observe commission of crime, patrol, and investigation were all combined into pedestrian stop. This decision was made because pedestrian stops typically relate to either observing a crime or suspicious behavior, occur during a routine patrol, or as part of an investigation. Serving an eviction order involves a similar structural process as serving a search or arrest warrant, so it was combined with serving a warrant.

The remaining two types of contact, subject initiated and collateral damage, are significant outliers. One involves a man who was killed by a stray bullet shot from a nearby police officer while involved in an undercover sting operation. The subject 
initiated case involved the subject, Joshua Scism, appeared to start an argument with undercover, plain clothes detectives and threatened them before they announced they were the police. Neither of these cases fit logically into any other type of contact. They also represent one white and one black subject, so for the purposes of statistical analysis of the contact_type_condensed variable, they were treated as missing values.

This process produced four types of contact: Call for service, traffic stop, pedestrian stop, and serving a warrant. There was still an issue of low frequency for serving a warrant $(n=9)$. To resolve this, the variable was further grouped into two types of contact. Traffic and pedestrian stops both involve officers choosing to stop the subject, and form a logical grouping together. Calls for service and serving a warrant are both forms of contact that involve an external decision maker (dispatch or judge) directing the police to make contact with a specific individual. These two types of contact were also grouped together. The defining feature of these two types of contact is the nature of the decision to make contact; either internal decisions made by the officer to make contact, or external decisions made by a third party, directing the contact with the subject. 
Table 6: Frequencies for Type of Contact and Contact Type Condensed Variables

\begin{tabular}{lrrr}
\hline type_of_contact & $f$ & $\%$ & Cum\% \\
\hline Call for Service & 57 & 57.0 & 57.0 \\
Traffic Stop & 17 & 17.0 & 74.0 \\
Investigation & 3 & 3.0 & 77.0 \\
Serve Warrant & 7 & 7.0 & 84.0 \\
Pedestrian Stop & 9 & 9.0 & 93.0 \\
Patrol & 2 & 2.0 & 95.0 \\
Serve Eviction Order & 2 & 2.0 & 97.0 \\
Observe Commission of Crime & 1 & 1.0 & 98.0 \\
Subject Initiated & 1 & 1.0 & 99.0 \\
Collateral Damage & 1 & 1.0 & 100.0 \\
\hline Total & 100 & 100.0 &
\end{tabular}

\begin{tabular}{llrrrr}
\hline contact_type_condensed & $f$ & $\%$ & Valid \% & Cum\% \\
\hline Valid & Call for Service/Serve Warrant & 66 & 66 & 67.4 & 67.4 \\
& Traffic/Pedestrian Stop & 32 & 32 & 32.6 & 100.0 \\
& Total & 98 & 98 & 100.0 & \\
Missing & System & 2 & 2 & & \\
\hline Total & 100 & 100 & &
\end{tabular}

\section{Call_reason and call_reason_condensed}

In news stories featuring a call for service, each stated reason for a call was initially coded using manifest coding. During the second phase, it was recoded into a latent code from the coding scheme. Often this process involved a manifest code such as "request for a welfare check for her son" being recoded into the latent code "Call: Welfare Check". In total, there were 16 different reasons why calls for service occurred, and they were combined into the call_reason variable during phase three. Half of those reasons occurred only once $(n=1)$ while the remaining eight reasons occurred with a frequency of 4 to 11 . Table 7 below provides frequencies for call_reason.

Due to low frequencies, these 16 values for call_reason were condensed into fewer values, creating the variable call_reason_condensed. Some of these values 
logically fit with each other. Calls about suicidal persons were added to "welfare check", and the abduction and hostage situation were added to domestic disturbance. "Weapons violation" and "shots fired" were added to "Armed, threatening subject". "Noise complaint" was added to "public disturbance". The remaining were combined into "Other".

Table 7: Call_Reason and Call_Reason_Condensed Variables

\begin{tabular}{lrrr}
\hline call reason & $f$ & $\%$ & Cum\% \\
\hline Domestic Disturbance & 11 & 19.3 & 19.3 \\
Welfare Check & 7 & 12.3 & 31.6 \\
Armed, Threatening Subject & 7 & 12.3 & 78.9 \\
Robbery & 6 & 10.5 & 42.1 \\
Public Disturbance & 5 & 8.8 & 50.9 \\
Shots Fired & 5 & 8.8 & 59.6 \\
Suicidal Person & 4 & 7.0 & 66.7 \\
Weapons Violation & 4 & 7.0 & 86.0 \\
Abduction & 1 & 1.8 & 87.7 \\
Hostage Situation & 1 & 1.8 & 89.5 \\
Criminal Tresspass & 1 & 1.8 & 91.2 \\
Fake Reason & 1 & 1.8 & 93.0 \\
Noise Complaint & 1 & 1.8 & 94.7 \\
Pedestrian on Highway & 1 & 1.8 & 96.5 \\
Prisoner Escape & 1 & 1.8 & 98.2 \\
Traffic Violation & 1 & 1.8 & 100.0 \\
\hline Total & 57 & 100.0 &
\end{tabular}

\begin{tabular}{lrrr}
\hline call_reason_condensed & $f$ & $\%$ & Cum\% \\
\hline Armed, Threatening Subject & 16 & 28.1 & 91.2 \\
Domestic Disturbance & 13 & 22.8 & 22.8 \\
Welfare Check & 11 & 19.3 & 42.1 \\
Robbery & 6 & 10.5 & 52.6 \\
Public Disturbance & 6 & 10.5 & 63.2 \\
Other & 5 & 8.8 & 100.0 \\
\hline Total & 100 & 100.0 &
\end{tabular}

\section{Traffic_stop_reason}

This variable includes all the reasons given for traffic stops within the content analysis data. As with call reason, this variable was initially coded during phase one using the exact phrase from the news report. During phase two it was latent coded into 
the values found in Table 8 . Phase three involved combining all latent codes into the variable for those cases whose type_of_contact value equals "traffic stop". This variable was not further condensed to increase the counts within each value. Given there are only 17 cases with values in this variable, combining them further would have little statistical value and would only dilute the meaning of each value. Missing values in this variable constitute all other cases within type_of_contact.

Table 8: Traffic_Stop_Reason Variable

Frequencies

\begin{tabular}{llrrrr}
\hline traffic_stop_reason & $f$ & $\%$ & Valid \% & Cum\% \\
\hline Valid & Traffic Violation & 8 & 8.0 & 47.1 & 47.1 \\
& Detain Suspect & 3 & 3.0 & 17.6 & 64.7 \\
& Stolen Vehicle & 2 & 2.0 & 11.8 & 76.5 \\
& Question Suspect & 1 & 1.0 & 5.9 & 82.4 \\
& Loud Music & 1 & 1.0 & 5.9 & 88.2 \\
& Suspicious Activity & 1 & 1.0 & 5.9 & 94.1 \\
& Suspended License & 1 & 1.0 & 5.9 & 100.0 \\
\cline { 2 - 6 } & Total & 17 & 17.0 & 100.0 & \\
Missing & System & 83 & 83.0 & & \\
Total & & 100 & 100.0 & & \\
\hline
\end{tabular}

\section{Pedestrian_stop_reason}

The final variable associated with type_of_contact includes values representing reasons for all pedestrian stops. As described in the construction of type_of_contact variable, pedestrian stops include several different kinds of interactions with people, typically on the street or in public spaces. Within pedestrian_stop_reason are six different string values for the pedestrian stop. These are outlined in Table 9 below with a descriptive value for each reason. Missing values in this variable constitute all other cases within type_of_contact. 
Table 9: Pedestrian_Stop_Reason Variable

Frequencies

\begin{tabular}{llrrrr}
\hline pedestrian_stop_reason & $f$ & $\%$ & Valid \% & Cum\% \\
\hline Valid & Investigate Scene & 2 & 2.0 & 13.3 & 13.3 \\
& Question Subject & 4 & 4.0 & 26.7 & 40.0 \\
& Shots Fired & 2 & 2.0 & 13.3 & 53.3 \\
& Surveillance & 3 & 3.0 & 20.0 & 73.3 \\
& Suspicious Behavior & 3 & 3.0 & 20.0 & 93.3 \\
& Unrelated Stop and Question & 1 & 1.0 & 6.7 & 100.0 \\
\cline { 2 - 6 } & Total & 15 & 15.0 & 100.0 & \\
Missing & System & 85 & 85.0 & & \\
Total & 100 & 100.0 & & \\
\hline
\end{tabular}

\section{Serve_warrant_type}

The serve_warrant_type variable includes the three types of warrants or orders that were mentioned within the content analysis data. This variable was generated in the first phase of the content analysis in the same manner as traffic stops and calls for service. During the second phase, these manifest codes were recoded using the latent code values in Table 10. These types of warrants or orders were then combined to create serve_warrant_type variable for those cases whose type_of_contact value equals "serve warrant". Missing values in this variable constitute all other cases within type_of_contact.

Table 10: Serve_Warrant_Type Variable

Frequencies

\begin{tabular}{llrrrr}
\hline \multicolumn{2}{l}{ serve_warrant_type } & $f$ & $\%$ & Valid \% & Cum\% \\
\hline Valid & Arrest & 6 & 6.0 & 66.7 & 66.7 \\
& Search & 2 & 2.0 & 22.2 & 88.9 \\
& Protective/Eviction & 1 & 1.0 & 11.1 & 100.0 \\
& Total & 9 & 9.0 & 100.0 & \\
\cline { 2 - 6 } Missing & System & 91.0 & & \\
Total & 100 & 100.0 & & \\
\hline
\end{tabular}

\section{Signs_of_mental_illness and mental_health}

Two variables in the data set involve mental health. The first, signs_of_mental_illness, comes from the Washington Post Data and is dichotomous, false $=0$ and true $=1$. Descriptive statistics are presented in Table 11 below. During phase 
one, phrases and quotes indicating the subject suffered from a mental illness were noted, and specifically the kind of mental illness was manifest coded. During the second phase, latent codes replaced the quotes from phase one. The final phase created the mental_health variable by combining latent codes into a single variable for all cases.

Table 11: Signs_of_Mental_Illness Variable

Descriptive Statistics

\begin{tabular}{lrrrrr}
\hline & N & Min & Max & Mean & SD \\
\hline signs_of_mental_illness & 100 & 0 & 1 & 0.24 & 0.429 \\
Valid N (listwise) & 100 & & & & \\
\hline
\end{tabular}

Mental_health is a string, nominal variable. This is not a diagnostic measure, as it is based solely on the reporting by journalists, which quotes family or friends who said what the subject was suffering from. In some instances, it is an unspecified mental illness, based on statements made to journalists along the lines of "[subject] had mental health problems..." The various non-clinical diagnoses are outlined in frequency Table 12 below. The mental_health variable applies to exactly the same cases as the signs_of_mental_illness variable from the Washington Post, meaning there appears to be interrater reliability on these variables insofar as the same subjects were flagged as having signs of mental illness. All cases within the sample with value $1=$ true in the signs_of_mental_illness variable also have values in the mental_health variable. 
Table 12: Mental_Health Variable

Frequencies

\begin{tabular}{llrrrr}
\hline mental_health & $f$ & $\%$ & Valid \% & Cum\% \\
\hline Valid & Bi Polar & 1 & 1.0 & 4.2 & 4.2 \\
& Dementia & 1 & 1.0 & 4.2 & 8.3 \\
& Depression & 3 & 3.0 & 12.5 & 20.8 \\
& Off Meds & 2 & 2.0 & 8.3 & 29.2 \\
& PTSD & 4 & 4.0 & 16.7 & 45.8 \\
& Schizophrenia & 3 & 3.0 & 12.5 & 58.3 \\
& Suicidal & 3 & 3.0 & 12.5 & 70.8 \\
& Unspecified & 7 & 7.0 & 29.2 & 100.0 \\
\cline { 2 - 5 } & Total & 24 & 24.0 & 100.0 & \\
Missing & 0 & 76 & 76.0 & & \\
Total & 100 & 100.0 & & \\
\hline
\end{tabular}

\section{Resistance}

Resistance was a complicated variable to develop through the content analysis.

During the first phase of coding, all seemingly resistance-relevant phrases or quotes were highlighted. In the second phase, several important decisions were made. First, in some cases no distinct mention of resistance was noted in news stories for a particular case. In such instances, the case is treated as missing this data rather than being coded as "no resistance”. Second, some forms of resistance are ambiguous. For example, refusing orders would technically apply to any time an order is given and the subject does not comply. However, because of the inconsistent use of terminology and descriptions between news stories, the decision was made to use a more conservative definition of refusing orders.

In this data set, resistance by refusing orders was coded for situations where some negotiation occurred or where some period of time transpired between the order being given and the subject being shot. If it appears the decision to shoot happened within moments of the order, the situation was not coded as refusing orders. This later situation 
might occur when the possibility of innocents being immediately harmed was a real factor in the series of events. For example, Michael Holt, age 35, was armed in a hotel lobby and had just shot a bystander moments before police arrived. While they technically told him to drop his weapon, they shot him almost immediately.

Resistance is also a complicated variable because each case might have multiple instances of resistance. A subject might refuse a traffic stop (latent coded as refusing orders) and then trigger a police chase (fled in vehicle), followed by a shootout (shot at officers). During the final phase of creating this variable, when a case included multiple forms of resistance, a subjective decision was made to select the resistance type that seemed most important. Typically, this was the first form of resistance. An exception to this was the barricade value of resistance. Often these situations began with some form of refusing orders or even threatening officers with a weapon. However, the act of barricading themselves and triggering some form of standoff or negotiations was so significant that the situation became defined by this act. Therefore, the case would be coded under the barricade value of resistance. Table 13 provides the frequencies for the resistance string variable.

Table 13: Resistance Variable Frequencies

\begin{tabular}{llrrrr}
\hline Resistance & & $f$ & $\%$ & Valid \% & Cum\% \\
\hline Valid & Threatened Officer with Weapon & 24 & 24.0 & 27.9 & 100.0 \\
& Fled on Foot & 16 & 16.0 & 18.6 & 55.8 \\
& Refused Orders & 14 & 14.0 & 16.3 & 72.1 \\
& Assault Officer & 12 & 12.0 & 14.0 & 14.0 \\
& Fled in Vehicle & 11 & 11.0 & 12.8 & 37.2 \\
& Barricade & 9 & 9.0 & 10.5 & 24.4 \\
\cline { 2 - 6 } & Total & 86 & 86.0 & 100.0 & \\
Missing & 999 & 14 & 14.0 & & \\
Total & & 100 & 100.0 & & \\
\hline
\end{tabular}




\section{Officer_time_on_force}

This variable is based on codes indicating how many years the officer or officers involved were on the force. Most cases did not provide this data. Some cases had as many as four involved officers whose time on the force was noted. There are four variables associated with this measurement, and when analyzed it is done using the multi-response process in IBM SPSS. This closely restricts what kind of statistical analysis is possible. A total of 52 officers across 32 cases are represented in this variable as depicted in table 14 below.

Table 14: \$officer_Time_on_Force Variable Frequencies

\begin{tabular}{|c|c|c|c|c|}
\hline \multicolumn{5}{|l|}{ \$officer_time_on_force } \\
\hline & & \multicolumn{2}{|c|}{ Responses } & \multirow[b]{2}{*}{ Cum $\%$} \\
\hline & & $f$ & $\%$ & \\
\hline \multirow{18}{*}{ Officer Time on Force ${ }^{\mathrm{a}}$} & 1 year & 5 & $9.6 \%$ & $9.6 \%$ \\
\hline & 2 years & 7 & $13.5 \%$ & $23.1 \%$ \\
\hline & 3 years & 3 & $5.8 \%$ & $28.8 \%$ \\
\hline & 4 years & 2 & $3.8 \%$ & $32.7 \%$ \\
\hline & 5 years & 5 & $9.6 \%$ & $42.3 \%$ \\
\hline & 6 years & 2 & $3.8 \%$ & $46.2 \%$ \\
\hline & 7 years & 2 & $3.8 \%$ & $50.0 \%$ \\
\hline & 8 years & 3 & $5.8 \%$ & $55.8 \%$ \\
\hline & 9 years & 3 & $5.8 \%$ & $61.5 \%$ \\
\hline & 11 years & 1 & $1.9 \%$ & $63.5 \%$ \\
\hline & 12 years & 4 & $7.7 \%$ & $71.2 \%$ \\
\hline & 13 years & 2 & $3.8 \%$ & $75.0 \%$ \\
\hline & 15 years & 4 & $7.7 \%$ & $82.7 \%$ \\
\hline & 16 years & 2 & $3.8 \%$ & $86.5 \%$ \\
\hline & 17 years & 1 & $1.9 \%$ & $88.5 \%$ \\
\hline & 19 years & 3 & $5.8 \%$ & $94.2 \%$ \\
\hline & 24 years & 1 & $1.9 \%$ & $96.2 \%$ \\
\hline & 25 years & 2 & $3.8 \%$ & $100.0 \%$ \\
\hline Total & & 52 & $100.0 \%$ & \\
\hline
\end{tabular}

a. Group 


\section{Quantitative and Qualitative Results}

Age

The age distribution for the stratified sample is shown in Figure 2. The age curve peaks between 25-30 years old. The age distribution shows police use deadly force on a slightly older cohort more often than on teenagers. This indicates perhaps that juvenile delinquency does not result in deadly force despite juvenile rates of criminal involvement. A one-sample Kolmogorov-Smirnov nonparametric test shows the age data is not normally distributed.

Figure 2: Age Distribution

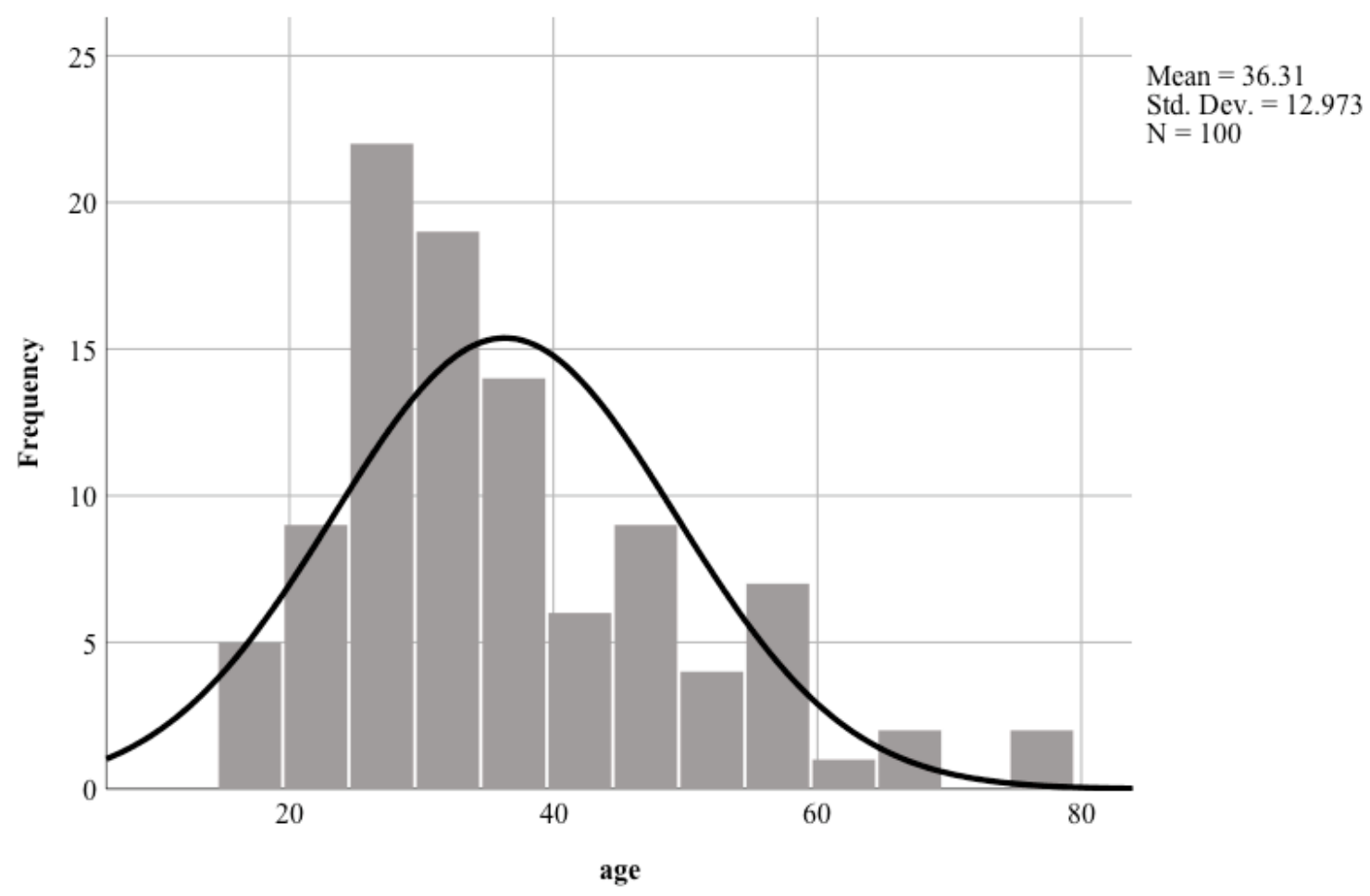

As we are interested in group differences by race, the age distribution was split between black and white subjects. This distribution is depicted in Figure 3. Black subjects under 44 are overrepresented within the sample, while white subjects over 44 are over represented. Table 14 shows the results of an independent samples t-Test analysis of age 
and race; black subjects were younger $(M=32.68, S D=11.781)$ than the white subjects $(M=39.94, S D=13.204), t(98)=2.901, p<.05$.

Figure 3: Age by Race

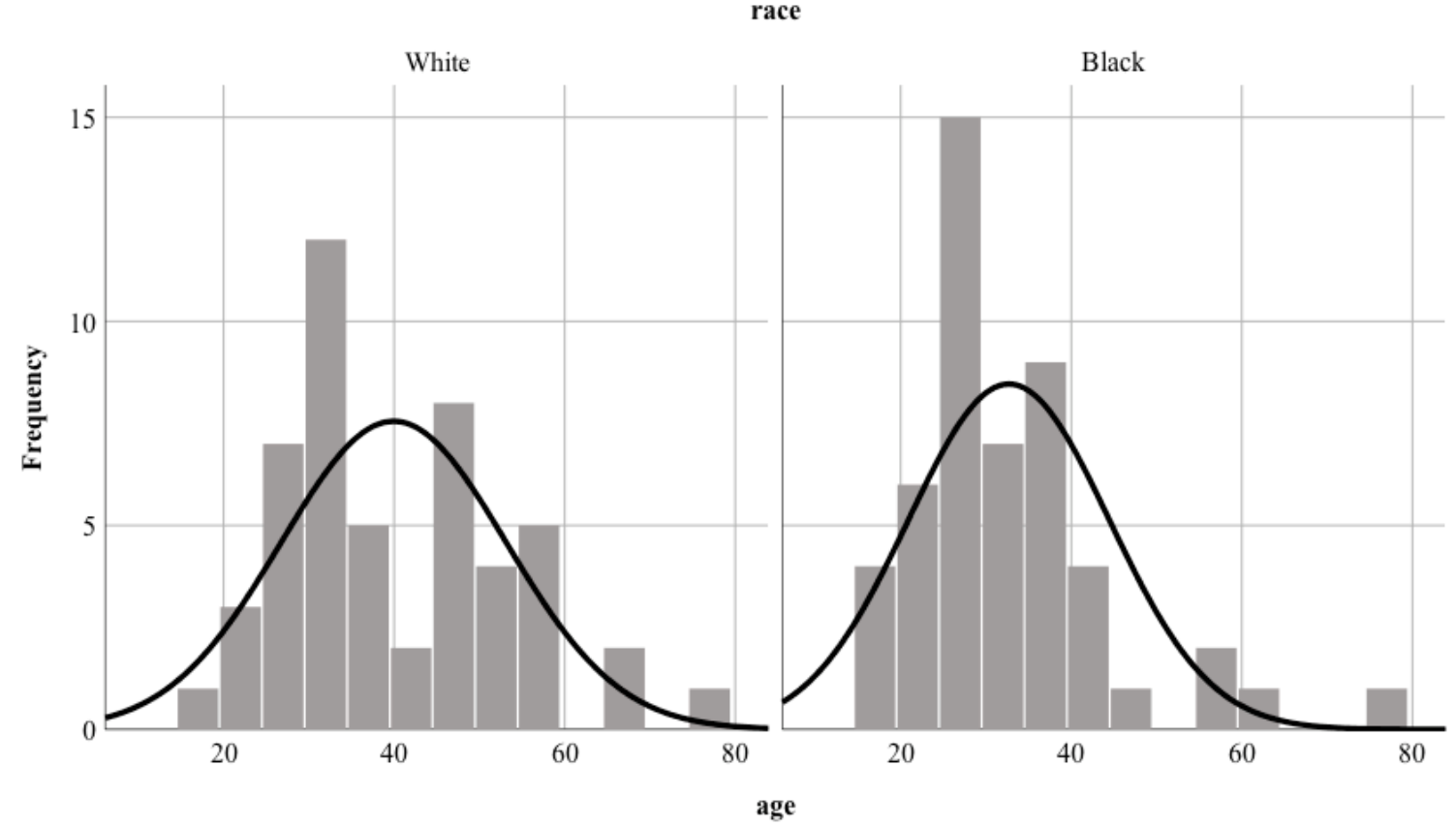

Table 15: Race and Age Independent Samples t-Test

Group Statistics

\begin{tabular}{lrrrrr}
\hline \multicolumn{2}{ll}{ race } & $\mathrm{N}$ & Mean & Std. & Std. \\
\hline age & White & 50 & 39.94 & 13.204 & 1.867 \\
& Black & 50 & 32.68 & 11.781 & 1.666 \\
\hline
\end{tabular}

Independent Samples Test

\begin{tabular}{|c|c|c|c|c|c|c|c|c|c|c|}
\hline & \multicolumn{4}{|c|}{ Levene's Test } & \multicolumn{3}{|c|}{ t-test for Equality of Means } & \multirow{2}{*}{\multicolumn{2}{|c|}{ 95\% Confidence }} \\
\hline & & \multirow[b]{2}{*}{$\mathrm{F}$} & \multirow[b]{2}{*}{ Sig. } & \multirow[b]{2}{*}{$\mathrm{t}$} & \multirow[b]{2}{*}{ df } & \multirow{2}{*}{$\begin{array}{l}\text { Sig. (2- } \\
\text { tailed) }\end{array}$} & \multirow{2}{*}{$\begin{array}{c}\text { Mean } \\
\text { Difference }\end{array}$} & \multirow{2}{*}{$\begin{array}{l}\text { Std. Error } \\
\text { Difference }\end{array}$} & & \\
\hline & & & & & & & & & Lower & Upper \\
\hline age & $\begin{array}{l}\text { Equal variances } \\
\text { assumed }\end{array}$ & 2.392 & 0.125 & 2.901 & 98 & 0.005 & 7.260 & 2.503 & 2.294 & 12.226 \\
\hline & $\begin{array}{l}\text { Equal variances } \\
\text { not assumed }\end{array}$ & & & 2.901 & 96.753 & 0.005 & 7.260 & 2.503 & 2.293 & 12.227 \\
\hline
\end{tabular}

These differences become more obvious when age is restructured into age ranges.

Figure 4, below, depicts group differences in frequencies for the age ranges. While black subjects outnumber white subjects through age 44 that shifts dramatically in the next age grouping of 45-54 years of age where there is only one black subject but 12 white subjects. 
A chi square test of independence was performed to examine the relationship between age range and race. The relationship was significant, however, there were $42.9 \%$ of cells with an expected count below the minimum of 5 . Therefore, we interpret the likelihood ratio instead, $\mathrm{L} \chi^{2}(6, \mathrm{~N}=100)=17.710, \mathrm{p}<.01$. There is a relationship between these two variables. Black subjects are more likely to be younger than white subjects within the sample. Those age 44 and younger include 45 black subjects (60\%) and 30 white subjects $(40 \%)$.

Figure 4: Frequency of Age Ranges by Race

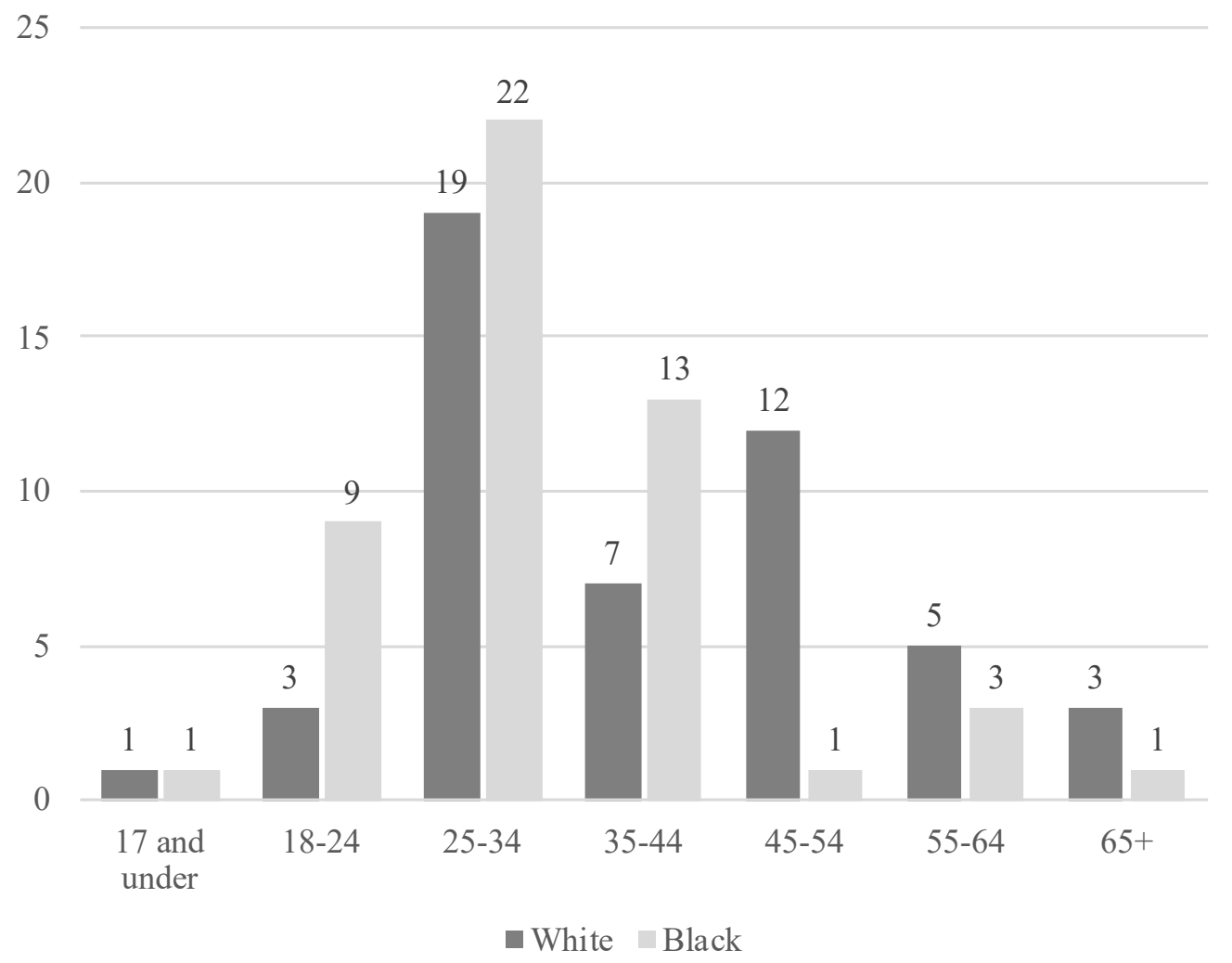

By itself, age is not a situational factor. Yet age could influence how a subject's behavior might be interpreted by police when they do come in contact with an individual. It is also important to note the variation in differences between the white and black subjects. Younger black men are over represented in counts while older white men are 
over represented. Generally speaking, we know younger, black men are overrepresented in formal contact with the criminal justice system which appears to be reflected in deadly force contact within the sample. It is possible the factors that influence the disparity in formal contact between young black and young white men are also influencing the disparity in use of deadly force. The content analysis did not reveal any obvious differences in the situations of young black subjects that might account for the disparity in this group.

The content analysis did reveal some interesting differences in underlying reasons for contact among the older age group which may account for this variation. The five black men over age 45 involve situations that implicate issues of mental health, including one case of dementia. Where law breaking occurred leading up to the police contact, it appeared to be directly related to the mental health issues of the black subjects. The white subjects age 45 and older tell a different story. While six incidents do involve issues of mental health, fourteen do not. Of those that do not, police were called regarding domestic disturbances involving child abuse $(n=1)$ or domestic violence $(n=5)$; were serving a search or arrest warrant $(n=3)$; were responding to a public disturbance $(n=2)$, trespassing $(n=1)$, or noise complaint; or conducting a pedestrian stop $(n=1)$. Similar situations were simply not represented among the black group. Table 16 below provides a crosstabulation of these differences. 
Table 16: Reason for Contact * Race Crosstabulation: Subjects 45 and Older

Count

\begin{tabular}{llrrr}
\hline & & \multicolumn{2}{c}{ race } & \\
\cline { 2 - 4 } Reason for Contact: & Mental Health Issues & 6 & 4 & 10 \\
Details & Domestic Violence & 5 & 0 & 5 \\
& Serving Warrant & 3 & 0 & 3 \\
& Public Disturbance & 2 & 0 & 2 \\
& Child Abuse & 1 & 0 & 1 \\
& Collateral Damage & 0 & 1 & 1 \\
& Noise Complaint & 1 & 0 & 1 \\
& Pedestrian Stop & 1 & 0 & 1 \\
& Tresspassing & 1 & 0 & 1 \\
\hline Total & & 20 & 5 & 25
\end{tabular}

The only similarities in reason for contact among this older group were the mental health issues experienced by the older white and black subjects. What stands in contrast among the oldest individuals, however, is mental health issues are implicated in all cases of older black subjects. The same is not true for older white subjects. Considering the significant likelihood ratio statistic and the qualitative analysis of the older subjects in the sample, it would appear there is a meaningful difference in use of deadly force between white and black subjects based on their age.

\section{Time of Day}

There were four missing cases in this variable, all of which are black subjects. Incidents occurred throughout the 24-hour period of a day, with the 6:00 am hour the only one without an incident. Higher frequencies of incidents tended to occur late at night compared to the rest of the day. Figure 6 below shows the distribution of cases across time. 


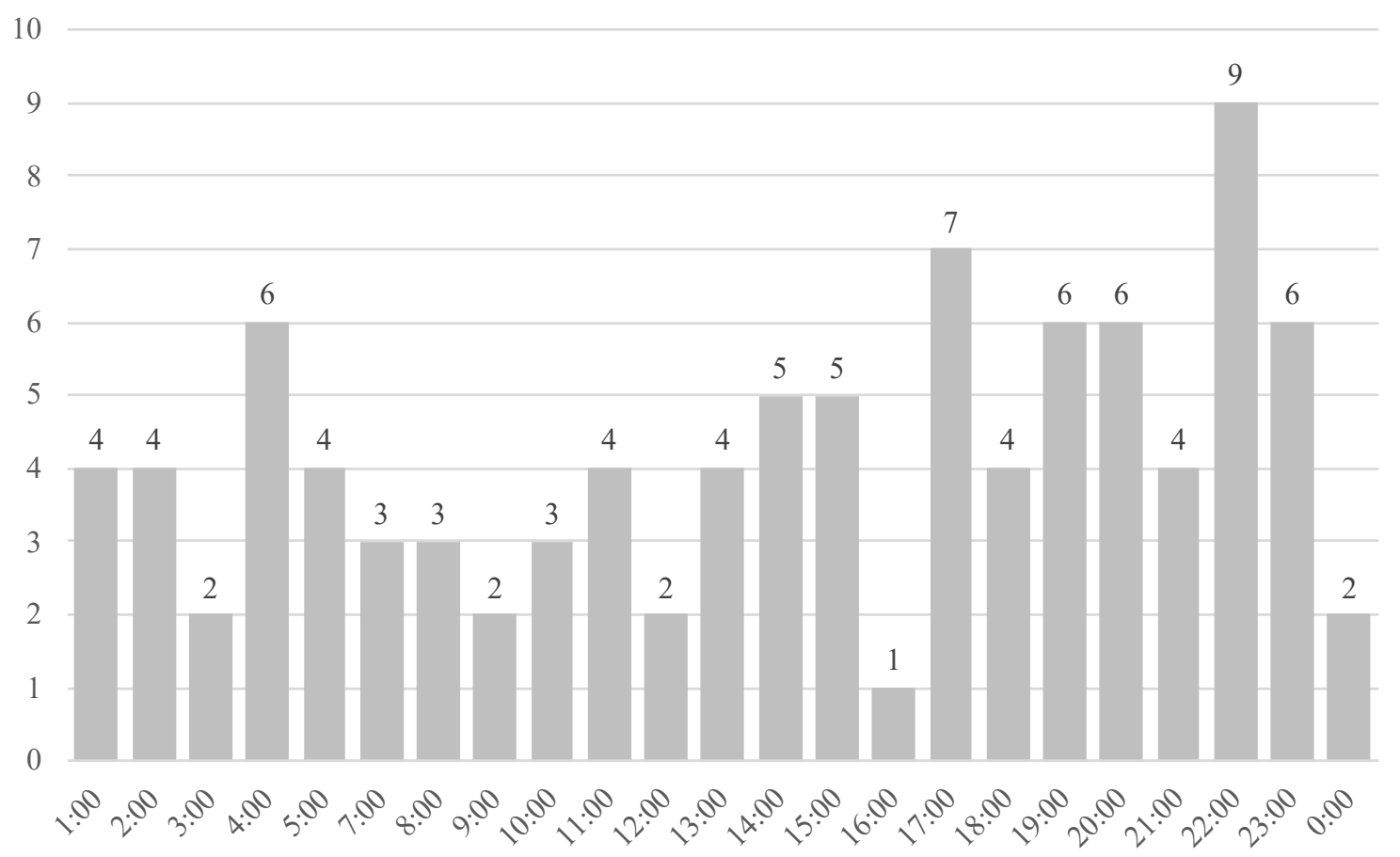

To resolve low frequency issues, the variable time period was used in the analysis. It did produce a crosstabulation with less than $20 \%$ of cells with expected counts below 5. Therefore, race and time_period were analyzed with a chi-square test of independence, which produced a non-significant result, $X^{2}(5, N=96)=3.617, p=.606$, suggesting these variables are independent.

However, figure 7 below shows an interesting pattern between the two groups. For most of the day, incidents involving black subjects are relatively stable, with a dip only during the morning. Slightly more variation occurs within the white sample, with the most incidents occurring from the afternoon through the night hours, before tapering off during early morning and remaining low from morning through mid-day. Regardless, tests of independence of these variables indicate no significant relationship between race 
and the time of day of the situation. Further, no cases stood out during the qualitative analysis that indicated any particular differences that might contextualize this small variation. Previous research has suggested the officer fatigue may impact decision making during lethal force incidents (James et al., 2018), however, we find no statistical difference that might account for racial disparity in frequencies across time.

Figure 6: Time Period of Incidents by Race

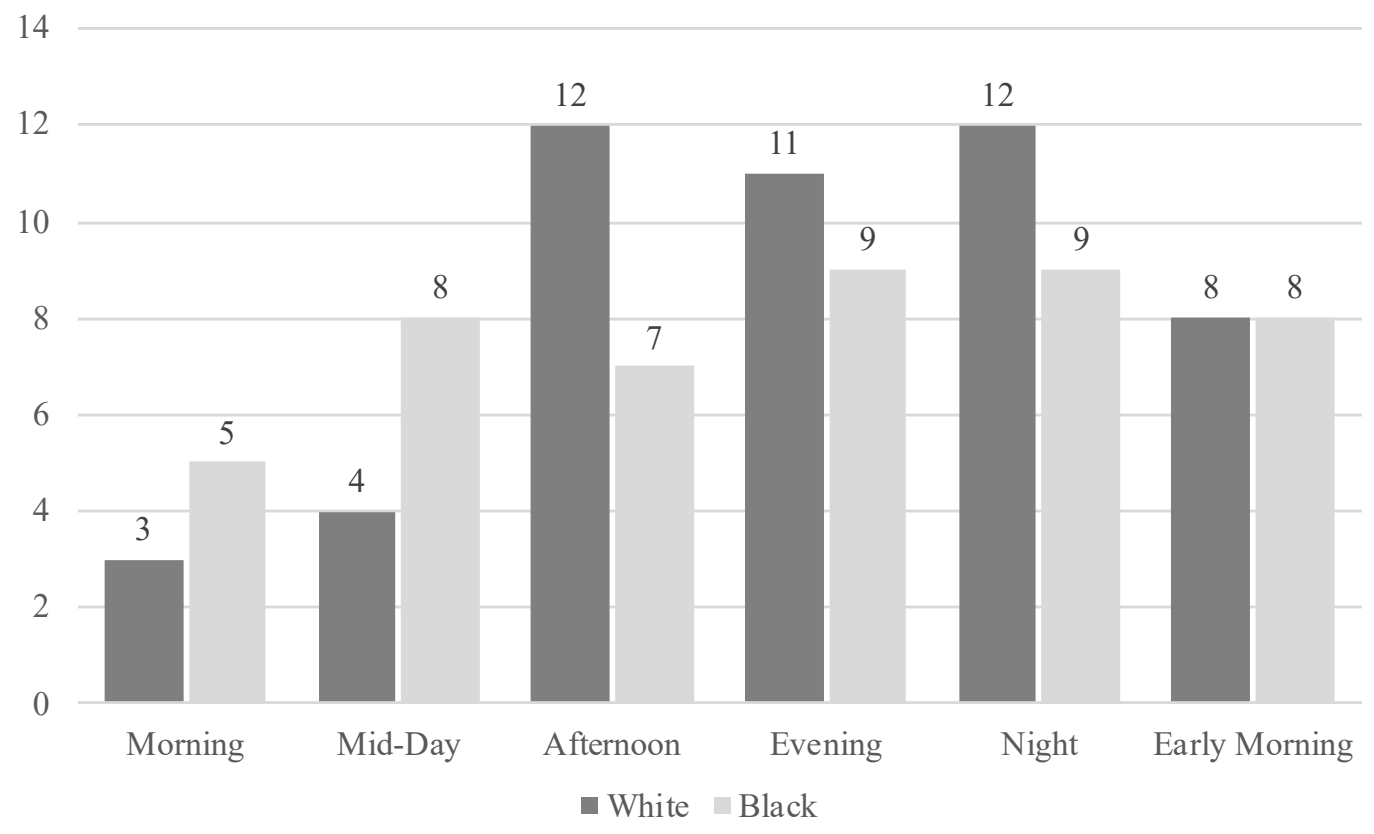

\section{Location}

If time of day is not an important situational difference between of white and black subjects, perhaps the physical location of the incident is. In an analysis of locations, it was found that $60 \%$ of all incidents occur in either a house or on the street. An additional $8 \%$ occur at an apartment, and 5\% occur in an apartment common area. Incidents in a parking lot comprise $5 \%$ of locations as well. Beyond that, the remaining 
12 locations have between 1-3 incidents each, representing 1-3\% of total incidents (refer to the section on location variable construction for details.)

Some notable patterns emerge when we use crosstabulation of the location_condensed variable and race, as seen in Table 17. First, we see that within the white subjects, $46 \%$ of incidents occur at a house, while $32 \%$ occur on the street.

Conversely, only $6 \%$ of incidents with black subjects occur at a house, while $56 \%$ occur on the street. For black subjects, a greater percentage occur at an apartment or apartment common area $(22 \%)$ than for white subjects $(10 \%)$. The "other" value indicates less variation among these locations between the two groups.

Table 17: Location_Condensed * Race Crosstabulation

\begin{tabular}{|c|c|c|c|c|c|}
\hline \multirow{3}{*}{ location_condensed } & \multirow[b]{3}{*}{ House (house) } & \multirow[b]{3}{*}{ Count } & \multicolumn{2}{|c|}{ race } & \multirow[t]{2}{*}{ Total } \\
\hline & & & \multirow{2}{*}{$\begin{array}{r}\text { White } \\
23\end{array}$} & \multirow{2}{*}{$\frac{\text { Black }}{3}$} & \\
\hline & & & & & 26 \\
\hline & & $\%$ within Location & $88.5 \%$ & $11.5 \%$ & $100.0 \%$ \\
\hline & & $\%$ of Total & $23.0 \%$ & $3.0 \%$ & $26.0 \%$ \\
\hline & Street (street, alley, & Count & 16 & 28 & 44 \\
\hline & sidewalk, highway, & $\%$ within Location & $36.4 \%$ & $63.6 \%$ & $100.0 \%$ \\
\hline & & $\%$ of Total & $16.0 \%$ & $28.0 \%$ & $44.0 \%$ \\
\hline & Apartment (apartment, & Count & 5 & 11 & 16 \\
\hline & apt common area, & $\%$ within Location & $31.3 \%$ & $68.8 \%$ & $100.0 \%$ \\
\hline & & $\%$ of Total & $5.0 \%$ & $11.0 \%$ & $16.0 \%$ \\
\hline & Other (parking lot, & Count & 6 & 8 & 14 \\
\hline & $\begin{array}{l}\text { public area, train, } \\
\text { hotel mall, barn }\end{array}$ & $\%$ within Location & $42.9 \%$ & $57.1 \%$ & $100.0 \%$ \\
\hline & wooded area) & $\%$ of Total & $6.0 \%$ & $8.0 \%$ & $14.0 \%$ \\
\hline & Total & Count & 50 & 50 & 100 \\
\hline
\end{tabular}

These results indicate large differences between these four locations and the white and black subjects. The crosstabulation results also show us we meet the minimum 
expected counts for all cells and can therefore interpret the chi square statistic. The result is significant, with $X^{2}(3, N=100)=21.193, p<.001$. There is a relationship between race and the location of each situation that results in a deadly shooting. Black subjects and white subjects are likely to be shot by police in different locations.

While some cases were notable for their location, such as Jamal Parks, age 32, who was involved in a shootout with police on a commuter train, generally speaking the locations of each case were not particularly noteworthy by themselves. Location becomes more interesting when considered within the context of the type of contact for each case. We might expect that calls for service occur more often at houses or apartments rather than on the street. We could expect a traffic stop to involve an incident on a street, and not in a house. A chi square test of independence between location_condensed and contact_type_condensed produced a chi square result of $X^{2}(3, \mathrm{~N}=98)=16.647, p<.01$, tells us location and contact type are related. Considering we see that race and location are related, and location and type of contact are related, let us turn next to an analysis of type_of_contact and race to further explore these connections.

\section{Type of Contact}

Distribution in frequencies of the type_of_contact variable were not suitable for chi square test of independence, so we utilized the contact_type_condensed variable instead. In Figure 8 below we see more white subjects killed following calls for service and serving warrants, while more black subjects are killed following traffic and pedestrian stops. A chi square analysis indicates a significant relationship between type of contact and race, $\chi^{2}(1, \mathrm{~N}=100)=6.682, \mathrm{p}<.05$. 
Figure 7: Frequencies of Type of Contact by Race

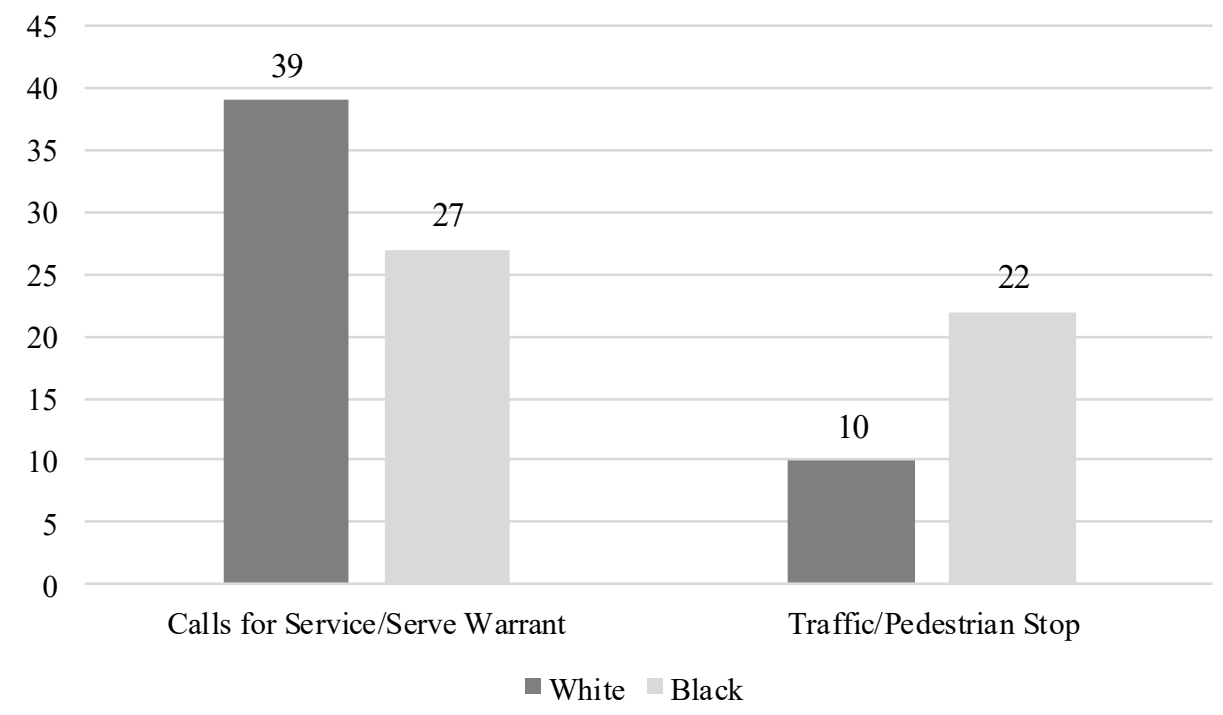

When police respond to a call for service or in serving a warrant, they are acting on behalf of the public or the courts. Dispatchers, or judges, have instructed an officer to make contact with a particular individual or at a particular place. Conversely, a traffic stop or pedestrian stop occurs when the officer makes the decision to contact the subject. While these underlying meanings are generalizations, each type of contact could be defined as resulting from decisions external to an officer or internal to an officer. Previous research has also indicated that some forms of contact are associated with greater uncertainty, and this uncertainty relates to the information that is known prior to contact (D. J. Johnson et al., 2018). In instances following a call for service or serving a warrant, much more is likely to be known about the subject or situation prior to the officer arriving on the scene, while very little may be known prior to a stop.

The results suggest white subjects are more likely to be killed following police actions related to external decision making, while black subjects are more likely to be 
killed following police actions related to internal decision making. This pattern may relate specifically to issues of biased policing and feelings of uncertainty prior to contact following different types of contact. It may also relate to differing ratios of policing in black communities compared to white communities. Analysis of these possible relationships falls outside the scope of this thesis. The pattern in type_of_contact may also be related to the public perception that black people are often killed by police under questionable circumstances. We cannot explore this possible relationship directly within the dataset as it exists now, but we can note some trends that emerged qualitatively.

The content analysis produced a latent code for when the department was criticized. Unfortunately, there is no specific latent code for when the department was not criticized. In some calls for service, particularly welfare checks for persons with mental illness issues, family indicated they understood the police did all they could and they did not blame the officers for the shooting. This would count as "no criticism" however it was not latent coded this way. The criticism variable is labeled $1=$ criticism, all else system missing. This data could be added in the future through an additional phase of coding for all cases to specifically identify if criticism or understanding of the situation was implicated in each case. For now, it would be wrong to interpret the missing data as "no criticism" because it was not coded in that manner during the content analysis. Some system missing data is likely an explicit "no criticism" value as in the example above. It is also likely some of the missing data is the result of no criticism noted in the reporting of the incident. 
From what data we do have, the department was criticized by family, friends, or the general public $31 \%$ of the time. Of that $31 \%$, criticism occurred more often in situations where the subject was black $(n=19)$ than when the subject was white $(n=13)$. We might infer this could reflect a higher percentage of traffic and pedestrian stops include criticism of the police than do calls for service and serving warrants. Indeed, there were $20(30.3 \%)$ instances of criticism amongst the 66 cases involving calls for service and serving a warrant. There were $11(34.4 \%)$ instances of criticism amongst the 32 cases involving traffic or pedestrian stops.

In summary, the statistical analysis demonstrates with significance there is a relationship between the type of contact and race when defined as contact resulting from internal or external decisions. This pattern indicates that black subjects are killed more often in situations where the officer is responsible for the decision to contact the subject. White subjects are killed more often in situations where the officer is following external orders to contact the subject. This finding shows one possible situational difference between black and white subjects relates to who decides to make formal contact with the subject.

It is possible that this difference between types of contact and race is also related to criticism of the police. This finding would appear to support the research by Tyler \& Wakslak (2004) on acceptance of police decisions. Further exploration and analysis are needed to determine the exact nature of any possible relationship here. However, it does appear this situational difference has implications for public opinion following instances 
of police use of deadly force, particularly in regard to activist messaging related to police bias.

\section{Calls for Service}

We now turn to an analysis of four primary types of contact included in detail. Calls for service account for $57 \%$ of the types of contact. Here we explore why calls for service occurred. The crosstabulation of the variable call_reason_condensed produced $58 \%$ of cells with an expected cell count below five. Therefore, we will interpret the likelihood ratio from the chi square test of independence and utilize the figures from the crosstab table for the analysis. Table 18 below displays the crosstab results for call_reason_condensed and race. The likelihood ratio is significant, $\mathrm{L} \chi^{2}(5, \mathrm{~N}=57)=$ $13.539, \mathrm{p}<.05$, which means there is a relationship between these two variables.

Table 18: Call Reasons Condensed * Race Crosstabulation

\begin{tabular}{|c|c|c|c|c|c|}
\hline & & & \multicolumn{2}{|c|}{ race } & \multirow[b]{2}{*}{ Total } \\
\hline & & & White & Black & \\
\hline Call Reasons & Domestic Disturbance & Count & 8 & 5 & 13 \\
\hline \multirow[t]{17}{*}{ Condensed } & & $\%$ within Call Reasons Condensed & $61.5 \%$ & $38.5 \%$ & $100.0 \%$ \\
\hline & & $\%$ of Total & $14.0 \%$ & $8.8 \%$ & $22.8 \%$ \\
\hline & Welfare Check & Count & 9 & 2 & 11 \\
\hline & & \% within Call Reasons Condensed & $81.8 \%$ & $18.2 \%$ & $100.0 \%$ \\
\hline & & $\%$ of Total & $15.8 \%$ & $3.5 \%$ & $19.3 \%$ \\
\hline & Robbery & Count & 0 & 6 & 6 \\
\hline & & $\%$ within Call Reasons Condensed & $0.0 \%$ & $100.0 \%$ & $100.0 \%$ \\
\hline & & $\%$ of Total & $0.0 \%$ & $10.5 \%$ & $10.5 \%$ \\
\hline & Public Disturbance & Count & 4 & 2 & 6 \\
\hline & & \% within Call Reasons Condensed & $66.7 \%$ & $33.3 \%$ & $100.0 \%$ \\
\hline & & $\%$ of Total & $7.0 \%$ & $3.5 \%$ & $10.5 \%$ \\
\hline & Armed, Threatening & Count & 9 & 7 & 16 \\
\hline & Subject & \% within Call Reasons Condensed & $56.3 \%$ & $43.8 \%$ & $100.0 \%$ \\
\hline & & $\%$ of Total & $15.8 \%$ & $12.3 \%$ & $28.1 \%$ \\
\hline & Other & Count & 3 & 2 & 5 \\
\hline & & \% within Call Reasons Condensed & $60.0 \%$ & $40.0 \%$ & $100.0 \%$ \\
\hline & & $\%$ of Total & $5.3 \%$ & $3.5 \%$ & $8.8 \%$ \\
\hline \multirow[t]{3}{*}{ Total } & & Count & 33 & 24 & 57 \\
\hline & & $\%$ within Call Reasons Condensed & $57.9 \%$ & $42.1 \%$ & $100.0 \%$ \\
\hline & & $\%$ of Total & $57.9 \%$ & $42.1 \%$ & $100.0 \%$ \\
\hline
\end{tabular}


White subjects outnumber black subjects for calls in all categories except robberies, where all calls for service were black subjects, representing the greatest disparity between groups. Of the robbery calls, three involved fairly violent encounters, with assaults, arson, and shootings of bystanders. Another was armed when police stopped him but had not harmed anyone during or after the commission of the robbery. One subject, Redel Jones, was the only black female in the sample who committed a crime prior to the deadly shooting. Ms. Jones stole $\$ 80$ from a convenience store and was later stopped by the police. Some discrepancies were reported about the incident between witnesses and official statements, and public protest followed this shooting. Mental illness is implicated in the case of Jawari Porter, who refused to pay for goods when exiting a grocery story. When confronted by store security, he pulled out a knife and was allowed to leave the store. Police attempted to stop him on the street, but he attacked an officer with the knife, lunging into the patrol car before being shot. Between the six calls to report a robbery, there is a wide range of context, from very violent situations to those that might better be classified as petty theft were it not for the weapon involved.

Welfare checks have the second greatest difference between groups, with white subjects receiving $81.8 \%$ of welfare check calls. Welfare check calls were all regarding persons with mental health issues $(\mathrm{n}=11)$. We will see later in the section on mental health, the vast majority $(87.5 \%)$ of cases involving persons exhibiting mental health issues begin as a call for service. More detailed analysis of the situations related to welfare checks will be conducted in the section on mental illness as these two variables are inextricably linked. 
Overall what we see in calls for service are statistically significant. There are small variations in counts between white and black subjects with the notable exceptions of robbery calls and welfare checks. The robbery call data is a particularly interesting finding that unfortunately cannot be easily explored in more depth here. Without data to compare robbery calls where the subject is not killed, we cannot reach any definitive conclusions. It does appear meaningful, however, that no deadly robbery calls involving white subjects exist within the sample.

\section{Traffic Stops}

Traffic stops accounted for $17 \%$ of types of contact. Black subjects were more than twice as likely to be killed following a traffic stop as were white subjects. This may relate to disparate frequencies in traffic stop contact in general, as found in previous research on racial disparity traffic stops (Morrow et al., 2017). Table 19 outlines each of the reasons for traffic stops within the sample, of which traffic violations was the most common reason for a stop. Due to small counts in this variable, our quantitative analysis will rely on frequencies and percentages to compare the groups.

Table 19: Traffic_Stop_Reason * Race Crosstabulation

\begin{tabular}{llrrr} 
Count & & & & \\
\hline & & race & \\
\cline { 3 - 4 } & & White & Black & Total \\
\hline Traffic Stop Reason & Traffic Violation & 2 & 6 & 8 \\
& Detain Suspect & 1 & 2 & 3 \\
& Stolen Vehicle & 0 & 2 & 2 \\
& Question Suspect & 0 & 1 & 1 \\
& Loud Music & 0 & 1 & 1 \\
& Suspicious Activity & 1 & 0 & 1 \\
& Suspended License & 1 & 0 & 1 \\
\hline Total & & 5 & 12 & 17
\end{tabular}


Traffic violations include very minor issues like broken taillights as well as more serious issues such as reckless driving. Police shootings following a traffic stop rarely occurred without some type of resistance. Data on resistance is missing from three of the traffic stop cases, including two white subjects and one black subject. Of the 14 remaining data points, ten subjects fled on foot or by vehicle, two assaulted the officer, one refused orders, and another offered no resistance. One case of a traffic violation stop is particularly noteworthy. This case was the only traffic stop where there was no resistance, and it also made national news.

Philando Castile was shot and killed following a traffic stop over a broken taillight. Mr. Castile held a concealed carry permit and was armed at the time of the stop. He informed the officer of this fact and moments later was shot as the officer misinterpreted a movement as Mr. Castile reached for his identification. His girlfriend was in the car with him and broadcast the event on Facebook Live. As the world literally watched him take his last breath, Mr. Castile became one of a growing number of black victims whose names have become a rallying cry against biased policing. Unlike most of the cases throughout this sample, Mr. Castile did not resist, did not threaten officers, and was not a threat to nearby civilians.

Mr. Castile's death may be an exceptional case that conveniently fits a narrative about police misuse of deadly force against black people. However, it should not be overlooked that when it comes to traffic stops resulting in deadly shootings, black subjects are over represented in the data. Of the $17 \%$ of shootings that occur after a traffic stop, more than $2 / 3$ involve black subjects. Recalling also the trend in criticism of police 
following types of contact involving stops, we might expect greater resistance following stops, and heightened criticism over stop decisions. While our sample of traffic stops is too small for robust statistical analysis, there is a disparity in these numbers. It is possible some statistically significant situational variation in traffic stops exists that a larger sample would be able to detect.

\section{Pedestrian Stop}

Of the 15 pedestrian stops that occurred, black subjects are overrepresented and make up $2 / 3$ of the category, as seen in table 20 . This racial disparity supports previous research that found a higher risk of receiving force for black subjects following pedestrian stop contact (Kramer \& Remster, 2018). Within the results, differences in frequencies are minimal or non-existent in half of the reasons for the stop. An equal number of white and black subjects were killed following pedestrian stops related to an investigation of a scene and questioning of a subject. Suspicious behavior included two white subjects and one black subject for a slight difference. However, in stops related to shots fired situations, surveillance scenarios, and an unrelated stop and question situation, only black subjects are represented.

Table 20: Pedestrian_Stop_Reason * Race Crosstabulation

\begin{tabular}{llrrr}
\hline Count & & \multicolumn{2}{c}{ race } & \\
\cline { 3 - 4 } & & White & Black & Total \\
\hline Pedestrian Stop & Investigate Scene & 1 & 1 & 2 \\
Reason & Question Subject & 2 & 2 & 4 \\
& Shots Fired & 0 & 2 & 2 \\
& Surveillance & 0 & 3 & 3 \\
& Suspicious Behavior & 2 & 1 & 3 \\
& Unrelated Stop and Question & 0 & 1 & 1 \\
\hline Total & & 5 & 10 & 15
\end{tabular}


Shots fired was associated with other forms of contact, including calls for service, which were more likely to involve white subjects. It may be that shots fired related stops simply occur more for black subjects because black subjects are more likely to experience a pedestrian stop. Meanwhile, white subjects may be more likely to experience a call for service for a shots fired call. In which case, the relevant factor would be the type of contact and not the reason for a call or a stop. It is possible surveillance situations are quite unique within this variable and may be better suited to classification in another type of contact.

The unrelated stop and question situation was particularly unique among the entire sample. This was an instance where an officer was at an apartment to confirm the resident had left per an eviction notice. While there, the officer saw a man, D'Angelo Stallworth, on the shared balcony of the apartment and he went to question him. The man was putting a child's bike into the storage closet on the balcony and the officer saw a handgun and mason jar of marijuana in the closet. A struggle over the gun ensued and Mr. Stallworth fled. The officer believed he still had the gun, and when Mr. Stallworth turned to look back while running across the apartment common area, the officer shot and killed him. He was unarmed, the gun had fallen in the struggle and was on the balcony where the officer was still standing. No white subjects in the sample were stopped by police while doing nothing out of the ordinary. This unique case notwithstanding, while black subjects are overrepresented in pedestrian stops, it is not clear that reasons for pedestrian stops are an otherwise important situational factor in explaining why there is racial disparity in use of deadly force within this type of contact. 


\section{Serve Warrant}

Only nine cases fit into this category of type_of_contact. Table 19 below outlines the racial breakdown for each type of warrant issued. We see that twice as many white subjects were killed following the serving of a warrant/order than black subjects. No black subjects were served with a search warrant and no white subjects were served with an eviction notice. The reasons for arrest warrants of white subjects include murder, sexual contact with a minor, felony drug charges, and one unspecified multiple warrant situation. One black subject was wanted for attempted murder, and the other was killed as collateral damage while officers attempted to arrest a passenger in her car on attempted murder charges (see section on collateral damage).

The two white subjects served with search warrants were related to cases involving drug dealing. One subject, Kenneth Stevens, was served with a no-knock search warrant for heroin and cocaine, and immediately threatened the officers, asking them who wants to die as they entered his apartment. The other subject, Phillip Burgess, initially allowed officers into his home with a search warrant for anabolic steroids, but soon became agitated and belligerent. He was shot multiple times including two shots from behind.

Table 21: Warrant Type * Race Crosstabulation

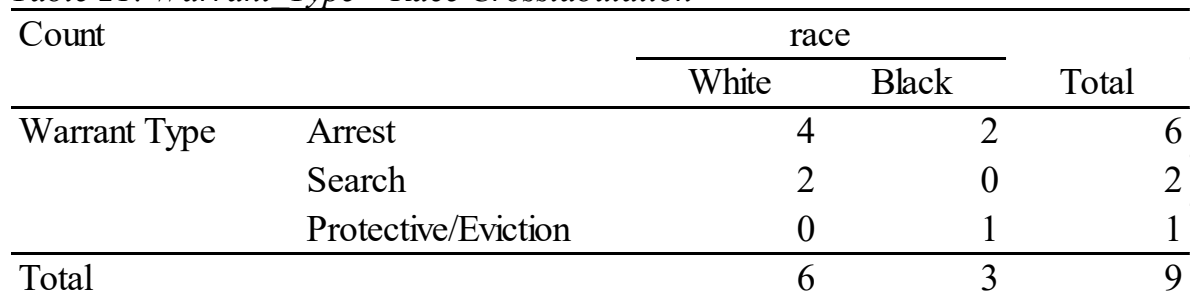

The final subject is a more complicated case. Dwayne Deshawn Ward was being served with an eviction notice and a protective order. He suffered from mental health 
issues and had assaulted his mother, whom he lived with, the week prior to the shooting. She chose not to press charges because she knew he needed mental health treatment, not jail. While serving the two orders, Mr. Ward threatened officers with a knife. They responded with pepper spray, a taser, and a police dog before shooting Mr. Ward. His mother criticized the department for his death, reiterating his need for mental health treatment.

The numbers here are too few for greater statistical analysis. Of these cases, all six of the white subjects were served with warrants for crimes or suspected crimes they had committed, while two of three black subjects were similarly situated. None of the white subjects were experiencing a mental health crisis at the time of the incident, while one of the black subjects was. And none of the white subjects were collateral damage. The variation in context between these groups appears small. It seems likely the act of serving a warrant or order is not an important factor in explaining the racial disparity in use of deadly force.

\section{Mental Health}

Out of the sample, 24 (24\%) of subjects exhibited signs of mental illness. Within those 24 , there were $16(66.7 \%)$ white subjects and $8(33.3 \%)$ black subjects. In a comparison of race and signs of mental illness, a chi-square test for independence was run. The results indicate these two variables are independent, with a non-significant chi square result of $X^{2}(1, \mathrm{~N}=100)=3.509, p=.061$. A few interesting findings in the crosstabulation table for these variables is that 6 of 9 black subjects were reported as having an unspecified mental illness, compared to 1 of 15 white subjects, as seen in table 
22. This may be an indication of differential mental health care between these two groups, or some other limitation in getting an official diagnosis. Recalling, however, these are non-clinical diagnoses and instead the reports from friends or family, we should be cautious about reading too much into the results related to diagnoses.

Table 22: Mental_Health * Race Crosstabulation Count

\begin{tabular}{|c|c|c|c|c|}
\hline & & \multicolumn{2}{|c|}{ race } & \multirow[b]{2}{*}{ Total } \\
\hline & & White & Black & \\
\hline \multirow[t]{8}{*}{ MentalHealth } & Bi Polar & 1 & & 1 \\
\hline & Dementia & 0 & & 1 \\
\hline & Depression & 3 & & 3 \\
\hline & Off Meds & 2 & & 2 \\
\hline & PTSD & 4 & & 4 \\
\hline & Schizophrenia & 1 & & 3 \\
\hline & Suicidal & 3 & & 3 \\
\hline & Unspecified & 1 & & 7 \\
\hline Total & & 15 & & 24 \\
\hline
\end{tabular}

The literature suggests police face more threatening situations when mental illness and substance abuse are actively co-occurring. Role of substance use in cases involving mental illness was at times hard to determine from the news reports. Many reports indicated a history of drug or alcohol abuse, but it was decided to only code reports that indicated it was known that the individual was actively using at the time of incident. Toxicology reports were sometimes cited, and occasionally family or friends noted the individual was actively using at the time they called the police. Only three cases indicated an active co-occurring substance use and mental illness, including one case involving alcohol and two cases involving illicit drugs. All three of these co-occurring instances involved white subjects and calls for service. In terms of co-occurring mental illness and substance use at the time of the deadly police shootings, there are not many cases, thus we cannot draw conclusions about any relationship between these factors. 
What we see in the data on mental illness suggest that some differences do exist between situations where white and black subjects are killed. There were more instances where white subjects were acting violently and threatening other people, compared with black subjects where violence and threats occurred only after police contact. There were more cases among white subjects of welfare check calls that resulted in the subject being killed. One particularly noteworthy pattern involves negotiations. As we see in the examples, some incidents involved an attempt at negotiation. There were all total 6 incidents that involved some substantive effort at negotiation (more than a few minutes of negotiations). Five of these incidents involved a white subject, while only one involved a black subject.

In summary, the statistical tests show us there is no relationship between race and mental illness. The qualitative analysis indicates that there is a great deal of variation in situations involving mental health. Enough variation, in fact, that it becomes hard to note any patterns that could potentially explain why twice as many white subjects are killed following incidents involving mental health. It is possible this variable is confounded by stigma around mental illness and likelihood of diagnosis and treatment between white and black communities. The results do support what the literature says about use of force and subjects with mental illness. Serious use of force is expected to increase when violent and threatening behavior is paired with mental illness (R. R. Johnson, 2011). We do see that trend across both groups.

\section{Resistance}

Black and white subjects were equally represented within the resistance variable. This alone is a significant finding as no other variable examined demonstrated exact 
parity on any situational factor. A total of 43 subjects from each group put up some form of resistance prior to the shooting. Of the six forms of resistance, assaulting an officer, fleeing in a vehicle, and refusing orders were somewhat evenly divided between the two groups, differing only in one or two counts as seen in table 23. Two forms of resistance, fleeing on foot and barricades, had the greatest discrepancy between subject groups. $81 \%$ of those who fled on foot were black, while $78 \%$ of those who barricaded themselves were white.

A chi square test of independence reveals the variables of race and resistance have a non-significant result of $X^{2}(5, N=86)=10.404, p=.065$. Two cells $(16.7 \%)$ in the table have an expected count less than 5. This finding suggests the two variables are independent of each other, although the finding is borderline significant. Considering fled on foot and barricade do have a more substantial variation, some other factor may be influencing the disparity in these two forms of resistance.

\begin{tabular}{llrrr}
\multicolumn{2}{l}{ Table 23: Resistance * Race Crosstabulation } \\
\hline Count & \multicolumn{2}{c}{ race } & \\
\cline { 2 - 4 } & & White & Black & Total \\
\hline Resistance & Threatened Officer & 14 & 10 & 24 \\
& Fled on Foot & 3 & $\mathbf{1 3}$ & 16 \\
& Refused Orders & 8 & 6 & 14 \\
& Assault Officer & 5 & 7 & 12 \\
& Fled in Vehicle & 6 & 5 & 11 \\
& Barricade & 7 & 2 & 9 \\
\hline Total & & 43 & 43 & 86
\end{tabular}

The situations where a subject might flee on foot versus barricade themselves are likely different. Perhaps because black subjects are more likely to be contacted in traffic and pedestrian stops, they are more likely to resist by fleeing on foot. Calls for service and serving a warrant are situations which tend to occur at a house or apartment. White 
subjects, who are more likely to be contacted at home, are in a position to resist by barricading themselves from inside a structure. The results here are a good example of the complexity of attempting to isolate specific situational factors that may be different between subjects.

\section{Officer Time on Force}

There were a total of 32 cases where officer characteristics were included in news reports. Sometimes the name or race of the officer was included in the report but typically the only information given was how many years they had been with the department. Some of these cases involved multiple officers who shot the subject. There were up to four officers involved in shooting the subject in three of the cases. There were two or more officers in 12 cases, and three or more officers in 5 cases. Their time on the force ranged between 1 and 25 years. The total number of officers whose time on the force was noted within the sample was 52 . Of that 52 , there is more data on the officers among the white group, $n=32$, than the black group, $n=20$.

Given that multiple cases have multiple officers, four total variables were made. First Officer applies to all 32 cases, while the second, third, and fourth officer variables only apply to those cases where there were multiple officers. In order to compare the overall frequency of time on the force for all officers across each of the four variables, they were transformed into a multiple response variable. This greatly limits our statistical options. However, given the literature implicates officer training and experience in the decision to use deadly force, we still wished to explore any trends that might be evident through frequencies and crosstabulations. 
What we found was $50 \%$ of officers involved had 7 or fewer years on the force. $75 \%$ of officers involved had 13 or fewer years on the force. See table 24 for an exact breakdown of this variable. The disparity in total frequency between the white and black subjects is confounded due to many more instances where news reports did not mention officer characteristics or explicitly said police were withholding that information in reports involving black subjects. Therefore, as a situational factor, we must be conservative in our conclusions drawn from comparisons between groups.

Table 24: \$officer Time on Force * Race Crosstabulation

\begin{tabular}{|c|c|c|c|c|c|}
\hline & & $\mathrm{ra}$ & & & \\
\hline & & White & Black & Total & Quartile \\
\hline Officer Time on Force ${ }^{a}$ & 1 year & 3 & 2 & 5 & \\
\hline & 2 years & 5 & 2 & 7 & $23.10 \%$ \\
\hline & 3 years & 2 & 1 & 3 & \\
\hline & 4 years & 0 & 2 & 2 & \\
\hline & 5 years & 4 & 1 & 5 & \\
\hline & 6 years & 2 & 0 & 2 & \\
\hline & 7 years & 0 & 2 & 2 & $50 \%$ \\
\hline & 8 years & 1 & 2 & 3 & \\
\hline & 9 years & 1 & 2 & 3 & \\
\hline & 11 years & 1 & 0 & 1 & \\
\hline & 12 years & 3 & 1 & 4 & \\
\hline & 13 years & 1 & 1 & 2 & $75 \%$ \\
\hline & 15 years & 4 & 0 & 4 & \\
\hline & 16 years & 2 & 0 & 2 & \\
\hline & 17 years & 1 & 0 & 1 & \\
\hline & 19 years & 2 & 1 & 3 & \\
\hline & 24 years & 0 & 1 & 1 & \\
\hline & 25 years & 0 & 2 & 2 & \\
\hline $\begin{array}{l}\text { Total } \\
\text { a. Paired group }\end{array}$ & & 32 & 20 & 52 & \\
\hline
\end{tabular}

The literature suggests that officer experience and training can lead to better accuracy in the decision to shoot. We do see that the median time on the force is 7 years, and nearly $25 \%$ of officers have only 1 or 2 years of experience. This may indicate support of previous research findings. However, without comparing officer time on the force with a legal analysis of each case, we really cannot conclude the less experienced 
officers were making poor shooting decisions. We need more information than what was obtainable through the content analysis before we can form any conclusions related to this situational factor. 


\section{Discussion}

This study sought to answer the question, are the situational factors in deadly police shootings different between black and white subjects? Underlying this research question is an attempt to understand what is happening in the use of deadly force within the black community. Polling research on public opinion that indicates black people expect less fair treatment from the criminal justice system than white people. This combined with accusations of outright racism and bias of police from activists make clear that some believe there is a difference in how police use force between these groups. Yet the research on deadly use of force remains scant. Are the examples of black victims of police violence rare outliers, used by activists to put a face to the broad sense the criminal justice system is not fair towards black Americans? Or are they statistically representative of a fundamental difference between when force is used against black or white subjects?

Actual data on use of deadly force shows us black subjects are disproportionally killed by police. And this disproportionality is not small; nearly $26 \%$ of the people killed by police from 2015-2017 were black. While twice as many white people were killed during that same period, as a proportion of the total US population, white people are underrepresented in police shootings. In $2017,60 \%$ of the US population was estimated to be white, while $13 \%$ were estimated to be black. This means black subjects are killed by police at a rate twice the size of their percentage of the total US population. Clearly something is occurring here.

The answering the research question we attempted to identify some situational factors that could be relevant in explaining why this disparity exists. Based on the 
literature on police use of force, several situational factors have previously been identified as having some relevance to police-citizen contact and use of force in general. These factors include the type of contact, such as a call for service or a stop and the reason for a call or stop, resistance from the subject, time of day, mental health of the subject, and officer experience. These factors were the focus of the content analysis and variables were constructed to identify elements of each. Two additional variables were considered. Age, as a demographic variable, and location of the incident.

\section{Primary Finding 1: Age}

We began the analysis with a demographic value, age, and found the relationship between age and race was statistically significant within the sample. Subjects age 44 and under were more likely to be black while subjects over 44 were more likely to be white. Not only were there statistical differences on the basis of age, but even within age cohorts, the reasons for the initial contact with police were different between white and black subjects. The qualitative analysis found that black subjects over 45 who were killed by police were all experiencing mental health issues at the time of the shooting, with one exception, an older man accidently killed by police. Mental illness is also implicated in six of the white subjects. However, most of the white subjects were actively engaged in crime or were being served arrest or search warrants. Qualitatively, the situations that result in contact are fundamentally different between white and black subjects in the older age cohorts.

The most interesting aspect of the age findings is in the two separate age curves for white and black subjects. Black subjects were younger than the white subjects by a 
mean age difference of approximately 7 years. Among younger subjects, more black subjects are killed than white subjects. The details of these incidents were not starkly different as in the older subjects. Future research may want to explore reasons for this variation. Why are white men engaging in more violent crime at an older age, resulting in their deaths following deadly force, than black men? One potential reason could simply relate to the disparity in incarceration rates of younger black men. Perhaps we have incapacitated so many black men that there just are not enough criminally inclined older black men around to encounter law enforcement.

\section{Primary Finding 2: Type of contact and public criticism}

The type of contact variable was constructed to categorize the broad reasons why each subject was contacted by police. Due to frequency issues within multiple values of this variable, it was recoded into two logical categories of types of contact: calls for service or serving warrants, and traffic or pedestrian stops. The chi square test of independence found a significant relationship between race and these two types of contact. Black subjects are over represented among contact that relies on officer discretion or internal decisions, which are traffic and pedestrian stops. White subjects are overrepresented when contact relies on external decisions, which are calls for service or serving warrants. This variable also is associated with criticism of police action.

The first step in the use of force process is the initial contact. This contact type is divided into two options, internal and external decisions, or stops and calls for service/serving a warrant respectively. Each individual contacted will either accept or not accept the attempt at contact. Those who accept the contact offer no resistance. Those 
who do not accept the contact will resist to some degree. When an individual resists the officer, the authority maintenance theory argues the officer will respond with some level of force (Alpert \& Dunham, 2004). When this force is deadly, the community is more likely to criticize the police following incidents that began with a stop, or an internal decision to make contact.

The current public debate focuses on a perceived difference in the situations where black and white subjects are killed by police. This criticism often hinges upon the idea that police officers are making bad choices, and its people of color, not white folks, who are the victims of these bad choices. As King (2019) points out in his social media post, an officer stopped the wrong car and then fired multiple shots into the car, injuring one black woman, before running away from the scene. While this example is not representative of common police practices, it is a salient example of the narrative of police discretion gone wrong.

The research question sought to discover if situational factors of police use of deadly force are different between white and black subjects. The data in this study has shown that more black subjects are killed following police officer decisions to make contact compared to external orders to make contact. This relationship between race and the type of contact is also statistically significant. In addition, deaths of black subjects resulted in more criticism than deaths of white subjects, and this criticism occurred at a greater rate following internal contact decisions. This suggests there is empirical validity to the activist claims that black people are killed under different circumstances than white people, and these different circumstances relate to police officer discretion. 


\section{Limitations}

The most significant limitation in this study is our inability to compare deadly force with instances where deadly force is used but the subject survives and with instances of non-lethal force. Expanding this study to include these instances would face the same issues previous research on use of force have encountered - limited and incomplete data. This study relies on national data but we do not have a comparable national data set on non-lethal force. In order to fully address the research question, and the underlying social concerns related to it, we have to be able to compare rates of deadly force with non-deadly force, across different types of contact, in response to different kinds of resistance, and between different groups of people.

The next major limitation to this study rests on the source of the data. There are a few potential issues with relying on news reports to generate factual data about police shootings. First is related to accuracy in reporting. While professional journalists are likely to make every effort to be accurate in their reporting, and news agencies regularly update stories when inaccuracies are found, it is possible that some details may have been unintentionally reported wrong. How language is used, such as using "home" to mean the place where a person lives but not necessarily a house, could result in some inaccuracies in the data. If phrases like "home" were coded as "house" but the journalist really just meant the place where the subject lived, it's possible the location was not a house. Relatively minor journalistic errors or lack of precision in language could be far more meaningful to research and thus represent an important limitation to this style of data collection. 
In addition to possible errors in facts as presented in news stories, not all stories provide all research-relevant data. A lot of data was missing throughout the various latent codes developed in the content analysis. Many potentially interesting pieces of data, such as the officer's time on the force, was so inconsistently reported that it was not available for all, or even most, cases. There appeared to be a trend of officials refusing to release any information about officers following incidents with black subjects, and little to no reported refusal among white subjects. In addition, the kinds of details presented in stories about white subjects and black subjects were not always the same. Criticism, for example, appeared to be noted far more frequently in stories about black subjects, and noted in particular with reference to Black Lives Matter and protests of police violence. This never occurred when criticism was mentioned among white subjects. What the effect is of these variations in how facts were presented is hard to determine.

Journalists may present stories that elaborate on either the subject's dangerousness or the police officer's recklessness in the situation. Further, locating news reports that stuck to the facts became increasingly difficult among the black subjects. As the cases moved from 2015 to 2017, a greater number of search results began to pop up from blogs or organizations with a possible pro-police or anti-police bias. Most results were obviously a local news station based on the web address, but others, particularly small regional newspapers, were harder to filter through and took a bit more effort to qualify as a valid source. Because of these challenges in the stories themselves, it was important that data collection focused on the most factually relevant points. Cross checking facts between news stories was also an important consideration when anything 
seemed particularly sensational. Ideally, further study on this subject could utilize official police reports in addition to news coverage to gain a balanced perspective.

\section{Challenges in statistical analysis}

Some cases are unique in ways that make them hard to compare to others in simplified statistical terms. These might be the extremely violent cases, like that of Christy Sheats, who murdered her teenage daughters minutes before police arrived and killed her. Or instances of collateral damage, like that of Felix Kumi, killed down the street from where an unrelated police sting operation was occurring. A sample of 100 is simply not large enough to account for these outlier cases. Yet it is the outliers that are more likely to fuel intense criticism of the police. An excellent example of this is the public reaction after Philando Castile was killed following a traffic stop in which he offered no resistance and had complied with officer instructions.

\section{Future research}

This exploratory study has identified several situational factors that appear relevant to deadly police shootings. Future research should focus on differences in type of contact, subject age, location, and group outcomes in use of force. Comparisons of lethal and non-lethal force between these variables and the race of the subject would be an ideal next step. Missing in this study, but what would be particularly useful, would be some objective measure of seriousness or dangerousness of the situation. For example, not all robberies are very serious or dangerous, and measuring a call reason as "robbery" may miss important variation between groups. Research that includes and expands on these 
concepts would improve our understanding of the disparity in use of deadly force between black and white subjects.

Some additional variables could potentially be added to the analysis, including neighborhood or block level data. Most news stories state the 100-block of the incident. Future content analysis, or use of official data, could include this and allow for neighborhood or block level analysis. Some potentially important, location specific variables that were not be included in this study are related to neighborhood characteristics. Previous research indicates neighborhood context interacts heavily with police fear response and use of force. Particularly in comparisons between lethal and nonlethal force, local crime statistics would be interesting to compare based on microlocations of each incident. In order to untangle racial disparity in use of force, some of these confounding data points should also be considered.

\section{Conclusion}

This study, and others like it, are important for addressing the social concerns of communities of color. Whether beliefs that police actions are racially biased are factually accurate or not is secondary to the impact such beliefs have on police legitimacy. As long as communities of color believe the police and the criminal justice system will not treat them fairly, police legitimacy will suffer. As long as police are seen as illegitimate actors within that community, more scrutiny and protest will occur when severe and deadly force is used. Future research in this area has the potential to shed light on these issues, contextualizing and perhaps validating the experiences of communities of color. 
Hopefully such research would also inspire change in use of deadly force policies, for the betterment of all communities. 


\section{References}

Akinola, M., \& Mendes, W. B. (2012). Stress-induced cortisol facilitates threat-related decision making among police officers. Behavioral Neuroscience, 126(1), 167-174. https://doi.org/10.1037/a0026657

Alpert, G. P. (2015). Police Use of Force and the Suspect with Mental Illness. Criminology \& Public Policy, 14(2), 277-283. https://doi.org/10.1111/17459133.12128

Alpert, G. P., \& Dunham, R. G. (2004). Understanding Police Use of Force: Officers, Suspects, and Reciprocity. Cambridge University Press.

Bolger, P. C. (2015). Just Following Orders: A Meta-Analysis of the Correlates of American Police Officer Use of Force Decisions. American Journal of Criminal Justice, 40(3), 466-492. https://doi.org/10.1007/s12103-014-9278-y

Brown, A. (2019). Key findings on Americans' views of race in 2019. Retrieved from https://www.pewresearch.org/fact-tank/2019/04/09/key-findings-on-americansviews-of-race-in-2019/

Charbonneau, A., Spencer, K., \& Glaser, J. (2017). Understanding Racial Disparities in Police Use of Lethal Force: Lessons from Fatal Police-on-Police Shootings. Journal of Social Issues, 73(4), 744-767. https://doi.org/10.1111/josi.12246

Correll, J., Hudson, S. M., Guillermo, S., and Ma, D. S. (2014). The Police Officer's Dilemma_A Decade of Research on Racial Bias, 5, 201-213.

Correll, J., Park, B., Judd, C. M., Wittenbrink, B., Sadler, M. S., \& Keesee, T. (2007). Across the Thin Blue Line: Police Officers and Racial Bias in the Decision to Shoot. Journal of Personality and Social Psychology, 92(6), 1006-1023. https://doi.org/10.1037/0022-3514.92.6.1006

Deane, M. W., Steadman, H. J., Borum, R., Veysey, B. M., \& Morrissey, J. P. (1999). Emerging Partnerships Between Mental Health and Law Enforcement. Psychiatric Services, 50(1), 99-101. https://doi.org/10.1176/ps.50.1.99

Fingerhut, H. (2017). Deep racial, partisan divisions in Americans' views of police officers. Retrieved from http://www.pewresearch.org/fact-tank/2017/09/15/deepracial-partisan-divisions-in-americans-views-of-police-officers/

Friedrich, B. R. J. (1980). Police use of force: Individuals, situations, and organizations. The Annals of the American Academy of Political and Social Science, 252(1), 8297.

James, L., James, S., \& Vila, B. (2018). The impact of work shift and fatigue on police officer response in simulated interactions with citizens. Journal of Experimental Criminology, 14(1), 111-120. https://doi.org/10.1007/s11292-017-9294-2

James, L., Vila, B., \& Daratha, K. (2013). Results from experimental trials testing participant responses to White, Hispanic and Black suspects in high-fidelity deadly force judgment and decision-making simulations. Journal of Experimental Criminology, 9(2), 189-212. https://doi.org/10.1007/s11292-012-9163-y

Johnson, D. J., Cesario, J., \& Pleskac, T. J. (2018). How prior information and police experience impact decisions to shoot. Journal of Personality and Social Psychology, 
115(4), 601-623. https://doi.org/10.1037/pspa0000130

Johnson, R. R. (2011). Suspect Mental Disorder and Police Use of Force. Criminal Justice and Behavior, 38(2), 127-145. https://doi.org/10.1177/0093854810388160

Kahn, K. B., \& Davies, P. G. (2017). What Influences Shooter Bias? The Effects of Suspect Race, Neighborhood, and Clothing on Decisions to Shoot. Journal of Social Issues, 73(4), 723-743. https://doi.org/10.1111/josi.12245

Kahn, K. B., Steele, J. S., McMahon, J. M., \& Stewart, G. (2017). How suspect race affects police use of force in an interaction over time. Law and Human Behavior, 41(2), 117-126. https://doi.org/10.1037/lhb0000218

Kaminski, R. J., Digiovanni, C., \& Downs, R. (2004). The Use of Force between the Police and Persons with Impaired Judgment. Police Quarterly, 7(3), 311-338. https://doi.org/10.1177/1098611103253456

Kenworthy, J. B., Barden, M. A., Diamond, S., \& del Carmen, A. (2011). Ingroup identification as a moderator of racial bias in a shoot-no shoot decision task. Group Processes and Intergroup Relations, 14(3), 311-318. https://doi.org/10.1177/1368430210392932

King, S. (2019). No Title. Retrieved from https:/www.facebook.com/shaunking/videos/1996627390632026/

Klinger, D. A. (2012). On the problems and promise of research on lethal police violence: A research note. Homicide Studies, 16(1), 78-96. https://doi.org/10.1177/1088767911430861

Kramer, R., \& Remster, B. (2018). Stop, Frisk, and Assault? Racial Disparities in Police Use of Force During Investigatory Stops. Law and Society Review, 52(4), 960-993. https://doi.org/10.1111/lasr.12366

Langton, L., \& Durose, M. (2013). Police Behavior during Traffic and Street Stops, 2011. Bureau of Justice Statistics, (September), 1-22. https://doi.org/10.1177/1098611115604449

Matter, B. L. (n.d.). Herstory. Retrieved from https://blacklivesmatter.com/about/herstory/

Morabito, M. S., \& Socia, K. M. (2015). Is Dangerousness a Myth? Injuries and Police Encounters with People with Mental Illnesses. Criminology and Public Policy, 14(2), 253-276. https://doi.org/10.1111/1745-9133.12127

Morrow, W. J., White, M. D., \& Fradella, H. F. (2017). After the Stop: Exploring the Racial/Ethnic Disparities in Police Use of Force During Terry Stops. Police Quarterly, 20(4), 367-396. https://doi.org/10.1177/1098611117708791

Nieuwenhuys, A., Oudejans, R. R. D., \& Savelsbergh, G. J. P. (2012). Shoot or don't shoot? Why police officers are more inclined to shoot when they are anxious. Emotion, 12(4), 827-833. https://doi.org/10.1037/a0025699

Nix, J., Campbell, B. A., Byers, E. H., \& Alpert, G. P. (2017). A Bird's Eye View of Civilians Killed by Police in 2015: Further Evidence of Implicit Bias. Criminology and Public Policy, 16(1), 309-340. https://doi.org/10.1111/1745-9133.12269

Post, T. W. (2017). Fatal Force [Data file]. Retrieved from https://github.com/washingtonpost/data-police-shootings 
Rojek, J., Rosenfeld, R., \& Decker, S. (2012). Policing race: The racial stratification of searches in police traffic stops. Criminology, 50(4), 993-1024. https://doi.org/10.1111/j.1745-9125.2012.00285.x

Ruiz, J., \& Miller, C. (2004). An Exploratory Study of Pennsylvania Police Officers' Perceptions of Dangerousness and Their Ability to Manage Persons with Mental Illness. Police Quarterly, 7(3), 359-371. https://doi.org/10.1177/1098611103258957

Shane, J. M., Lawton, B., \& Swenson, Z. (2017). The prevalence of fatal police shootings by U.S. police, 2015-2016: Patterns and answers from a new data set. Journal of Criminal Justice, 52(March), 101-111. https://doi.org/10.1016/j.jcrimjus.2017.05.001

Sim, J. J., Correll, J., \& Sadler, M. S. (2013). Understanding Police and Expert Performance: When Training Attenuates (vs. Exacerbates) Stereotypic Bias in the Decision to Shoot. Personality and Social Psychology Bulletin, 39(3), 291-304. https://doi.org/10.1177/0146167212473157

Smith, M. R., \& Alpert, G. P. (2007). Explaining police bias: A theory of social conditioning and illusory correlation. Criminal Justice and Behavior, 34(10), 1262 1283. https://doi.org/10.1177/0093854807304484

Tate, J., Jenkins, J., Rich, S., Muyskens, J., Elliot, K., Mellnik, T., \& Williams, A. (2016). How the Washington Post is examining police shootings in the United States. The Washington Post. Retrieved from https://www.washingtonpost.com/national/how-the-washington-post-is-examiningpolice-shootings-in-the-united-states/2016/07/07/d9c52238-43ad-11e6-8856f26de2537a9d_story.html

Terrill, W., \& Mastrofski, S. D. (2002). Terrill 2002 - Situational and Officer-Based determinants of police coercion.pdf. Justice Quarterly, 19(2), 215-248.

Terrill, W., \& Reisig, M. D. (2003). Neighborhood context and police use of force. Journal of Research in Crime and Delinquency, 40(3), 291-321. https://doi.org/10.1177/0022427803253800

Tyler, T. R., \& Huo, Y. J. (2002). Trust in the Law: Encouraging Public Cooperation with the Police and Courts. Russel Sage Foundation.

Tyler, T. R., \& Wakslak, C. J. (2004). Profiling and Police Legitimacy: Procedural Justice, Attributions of Motive, and Acceptance of Police Authority. Criminology, 42(2), 253-281.

Watson, A. C., Corrigan, P. W., \& Ottati, V. (2003). Police Officers' Attitudes Toward and Decisions About Persons With Mental Illness. Psychiatric Services, 55(1), 4953. https://doi.org/10.1176/appi.ps.55.1.49

Watson, A. C., Swartz, J., Bohrman, C., Kriegel, L. S., \& Draine, J. (2014). Understanding how police officers think about mental/emotional disturbance calls. International Journal of Law and Psychiatry, 37(4), 351-358. https://doi.org/10.1016/j.ijlp.2014.02.005

Worden, R. E. (2015). The "Cause" of Police Brutality: Theory and Evidence on Police Use of Force. In E. R. Maguire \& D. E. Duffee (Eds.), Criminal Justice Theory (2nd Ed., pp. 149-204). Routledge. 


\section{Appendix A: Variable Codebook}

\begin{tabular}{lllll} 
race & & & & \\
\hline & & Value & $f$ & $\%$ \\
\hline Standard Attributes & Label & $<$ none $>$ & & \\
& Type & Numeric & & \\
& Measurement & Nominal & & \\
& Role & Input & 50 & $50.0 \%$ \\
& 0 & White & 50 & $50.0 \%$ \\
\hline Valid Values & 1 & Black & &
\end{tabular}

age

\begin{tabular}{lll}
\hline & & Value \\
\hline Standard Attributes & Label & $<$ none $>$ \\
& Type & Numeric \\
& Measurement & Scale \\
& Role & Input \\
\hline $\mathrm{N}$ & Valid & 100 \\
& Missing & 0 \\
\hline Central Tendency and & Mean & 36.31 \\
Dispersion & Standard Deviation & 12.973 \\
& Percentile 25 & 27.50 \\
& Percentile 50 & 33.00 \\
& Percentile 75 & 44.50 \\
\hline
\end{tabular}

age_range

\begin{tabular}{lllrr}
\hline & & Value & $f$ & $\%$ \\
\hline Standard Attributes & Label & Age in Ranges & & \\
& Type & Numeric & & \\
& Measurement & Scale & & \\
& Role & Input & & \\
\hline $\mathrm{N}$ & Valid & 100 & & \\
& Missing & 0 & & \\
\hline Central Tendency and & Mean & 3.70 & & \\
Dispersion & Standard Deviation & 1.345 & 2 & $2.0 \%$ \\
& Percentile 25 & 3.00 & 41 & $41.0 \%$ \\
& Percentile 50 & 3.00 & 20 & $20.0 \%$ \\
& Percentile 75 & 4.50 & 13 & $13.0 \%$ \\
\hline Labeled Values & 1 & 17 and under & 8 & $8.0 \%$ \\
& 2 & $18-24$ & 4 & $4.0 \%$ \\
\hline
\end{tabular}


time_of_day

\begin{tabular}{|c|c|c|c|c|}
\hline & & Value & $f$ & $\%$ \\
\hline \multirow[t]{4}{*}{ Standard Attributes } & Label & Time of Day & & \\
\hline & Type & Numeric & & \\
\hline & Measurement & Ordinal & & \\
\hline & Role & Input & & \\
\hline \multirow[t]{23}{*}{ Valid Values } & $1: 00$ & & 4 & $4.0 \%$ \\
\hline & $2: 00$ & & 4 & $4.0 \%$ \\
\hline & $3: 00$ & & 2 & $2.0 \%$ \\
\hline & $4: 00$ & & 6 & $6.0 \%$ \\
\hline & $5: 00$ & & 4 & $4.0 \%$ \\
\hline & $7: 00$ & & 3 & $3.0 \%$ \\
\hline & $8: 00$ & & 3 & $3.0 \%$ \\
\hline & $9: 00$ & & 2 & $2.0 \%$ \\
\hline & $10: 00$ & & 3 & $3.0 \%$ \\
\hline & $11: 00$ & & 4 & $4.0 \%$ \\
\hline & $12: 00$ & & 2 & $2.0 \%$ \\
\hline & $13: 00$ & & 4 & $4.0 \%$ \\
\hline & $14: 00$ & & 5 & $5.0 \%$ \\
\hline & $15: 00$ & & 5 & $5.0 \%$ \\
\hline & $16: 00$ & & 1 & $1.0 \%$ \\
\hline & $17: 00$ & & 7 & $7.0 \%$ \\
\hline & $18: 00$ & & 4 & $4.0 \%$ \\
\hline & $19: 00$ & & 6 & $6.0 \%$ \\
\hline & 20:00 & & 6 & $6.0 \%$ \\
\hline & 21:00 & & 4 & $4.0 \%$ \\
\hline & $22: 00$ & & 9 & $9.0 \%$ \\
\hline & $23: 00$ & & 6 & $6.0 \%$ \\
\hline & $24: 00$ & & 2 & $2.0 \%$ \\
\hline Missing Values & System & & 4 & $4.0 \%$ \\
\hline \multicolumn{5}{|l|}{ time_period } \\
\hline & & Value & $f$ & $\%$ \\
\hline \multirow[t]{4}{*}{ Standard Attributes } & Label & Time Period & & \\
\hline & Type & Numeric & & \\
\hline & Measurement & Ordinal & & \\
\hline & Role & Input & & \\
\hline \multirow[t]{6}{*}{ Valid Values } & 1 & Morning & 8 & $8.0 \%$ \\
\hline & 2 & Mid-Day & 12 & $12.0 \%$ \\
\hline & 3 & Afternoon & 19 & $19.0 \%$ \\
\hline & 4 & Evening & 20 & $20.0 \%$ \\
\hline & 5 & Night & 21 & $21.0 \%$ \\
\hline & 6 & Early Morning & 16 & $16.0 \%$ \\
\hline Missing Values & System & & 4 & $4.0 \%$ \\
\hline
\end{tabular}




\begin{tabular}{|c|c|c|c|c|}
\hline & & Value & $f$ & $\%$ \\
\hline \multirow[t]{4}{*}{ Standard Attributes } & Label & Location & & \\
\hline & Type & Numeric & & \\
\hline & Measurement & Nominal & & \\
\hline & Role & Input & & \\
\hline \multirow[t]{17}{*}{ Valid Values } & 1 & House & 26 & $26.0 \%$ \\
\hline & 2 & Street & 34 & $34.0 \%$ \\
\hline & 3 & Apartment & 8 & $8.0 \%$ \\
\hline & 4 & Apt Common Area & 5 & $5.0 \%$ \\
\hline & 5 & Parking Lot & 5 & $5.0 \%$ \\
\hline & 6 & Wooded Area & 2 & $2.0 \%$ \\
\hline & 7 & Barn & 1 & $1.0 \%$ \\
\hline & 8 & RV/Trailer Park & 2 & $2.0 \%$ \\
\hline & 9 & Duplex & 1 & $1.0 \%$ \\
\hline & 10 & Hotel & 3 & $3.0 \%$ \\
\hline & 11 & Alley & 3 & $3.0 \%$ \\
\hline & 12 & Sidewalk & 2 & $2.0 \%$ \\
\hline & 13 & Public Area & 1 & $1.0 \%$ \\
\hline & 14 & Train & 1 & $1.0 \%$ \\
\hline & 15 & Highway & 3 & $3.0 \%$ \\
\hline & 16 & Car & 2 & $2.0 \%$ \\
\hline & 17 & Mall & 1 & $1.0 \%$ \\
\hline \multicolumn{5}{|l|}{ location_condensed } \\
\hline & & Value & $f$ & $\%$ \\
\hline \multirow[t]{4}{*}{ Standard Attributes } & Label & 4 Value Location & & \\
\hline & Type & Numeric & & \\
\hline & Measurement & Nominal & & \\
\hline & Role & Input & & \\
\hline \multirow[t]{6}{*}{ Valid Values } & 1 & House (house) & 26 & $26.00 \%$ \\
\hline & 2 & $\begin{array}{l}\text { Street (street, alley, sidewalk, } \\
\text { highway, car) }\end{array}$ & 44 & $44.00 \%$ \\
\hline & & $\begin{array}{l}\text { Apartment (apartment, apt } \\
\text { common area, duplex, rv/trailer }\end{array}$ & & \\
\hline & 3 & $\operatorname{park}($ & 16 & $16.00 \%$ \\
\hline & & $\begin{array}{l}\text { Other (parking lot, public area, } \\
\text { train, hotel, mall, barn, wooded }\end{array}$ & & \\
\hline & 4 & area) & 14 & $14.00 \%$ \\
\hline
\end{tabular}


type_of_contact

\begin{tabular}{lllrr}
\hline & & Value & $f$ & $\%$ \\
\hline Standard Attributes & Label & Type of Contact & \\
& Measurement & Numeric & & \\
& Role & Nominal & \\
\hline Valid Values & 1 & Call for Service & 57 & $57.0 \%$ \\
& 2 & Traffic Stop & 17 & $17.0 \%$ \\
& 3 & Investigation & 3 & $3.0 \%$ \\
& 4 & Serve Warrant & 7 & $7.0 \%$ \\
& 5 & Pedestrian Stop & 9 & $9.0 \%$ \\
& 6 & Patrol & 2 & $2.0 \%$ \\
& 7 & Serve Eviction Order & 2 & $2.0 \%$ \\
& 8 & Observe Commission of Crime & 1 & $1.0 \%$ \\
& 9 & Subject Initiated & 1 & $1.0 \%$ \\
& 10 & Collateral Damage & 1 & $1.0 \%$ \\
\hline
\end{tabular}

contact_type_condensed

\begin{tabular}{lllrr}
\hline & & Value & $f$ & $\%$ \\
\hline Standard Attributes & Label & Contact type condensed & & \\
& Type & Numeric & \\
& Measurement & Nominal & \\
& Role & Input & 57 & $57.0 \%$ \\
& 1.00 & Call for Service & 17 & $17.0 \%$ \\
Valid Values & 2.00 & Traffic Stop & 9 & $9.0 \%$ \\
& 3.00 & Serve Warrant & 15 & $15.0 \%$ \\
\hline Missing Values & 4.00 & Pedestrian Stop & 1 & $1.0 \%$ \\
& 9.00 & Subject Initiated & 1 & $1.0 \%$ \\
\hline
\end{tabular}

call_reason

\begin{tabular}{|c|c|c|c|c|}
\hline & & Value & $f$ & $\%$ \\
\hline \multirow[t]{4}{*}{ Standard Attributes } & Label & Call Reason & & \\
\hline & Type & Numeric & & \\
\hline & Measurement & Nominal & & \\
\hline & Role & Input & & \\
\hline \multirow[t]{15}{*}{ Valid Values } & 1 & Domestic Disturbance & 11 & $11.0 \%$ \\
\hline & 2 & Welfare Check & 7 & $7.0 \%$ \\
\hline & 3 & Robbery & 6 & $6.0 \%$ \\
\hline & 4 & Public Disturbance & 5 & $5.0 \%$ \\
\hline & 5 & Shots Fired & 5 & $5.0 \%$ \\
\hline & 6 & Suicidal Person & 4 & $4.0 \%$ \\
\hline & 7 & Armed, Threatening Subject & 7 & $7.0 \%$ \\
\hline & 8 & Weapons Violation & 4 & $4.0 \%$ \\
\hline & 9 & Abduction & 1 & $1.0 \%$ \\
\hline & 10 & Hostage Situation & 1 & $1.0 \%$ \\
\hline & 11 & Criminal Trespass & 1 & $1.0 \%$ \\
\hline & 12 & Fake Reason & 1 & $1.0 \%$ \\
\hline & 13 & Noise Complaint & 1 & $1.0 \%$ \\
\hline & 14 & Pedestrian on Highway & 1 & $1.0 \%$ \\
\hline & 15 & Prisoner Escape & 1 & $1.0 \%$ \\
\hline
\end{tabular}




\begin{tabular}{|c|c|c|c|c|}
\hline & 17 & Traffic Violation & 1 & $1.0 \%$ \\
\hline Missing Values & System & & 43 & $43.0 \%$ \\
\hline \multicolumn{5}{|c|}{ call_reason_condensed } \\
\hline & & Value & $f$ & $\%$ \\
\hline \multirow[t]{4}{*}{ Standard Attributes } & Label & Call Reasons Condensed & & \\
\hline & Type & Numeric & & \\
\hline & Measurement & Nominal & & \\
\hline & Role & Input & & \\
\hline \multirow[t]{6}{*}{ Valid Values } & 1.00 & Domestic Disturbance & 13 & $13.0 \%$ \\
\hline & 2.00 & Welfare Check & 11 & $11.0 \%$ \\
\hline & 3.00 & Robbery & 6 & $6.0 \%$ \\
\hline & 4.00 & Public Disturbance & 6 & $6.0 \%$ \\
\hline & 7.00 & Armed, Threatening Subject & 16 & $16.0 \%$ \\
\hline & 11.00 & Other & 5 & $5.0 \%$ \\
\hline Missing Values & 999.00 & & 43 & $43.0 \%$ \\
\hline \multicolumn{5}{|c|}{ pedestrian_stop_reason } \\
\hline & & Value & $f$ & $\%$ \\
\hline \multirow[t]{4}{*}{ Standard Attributes } & Label & Pedestrian Stop Reason & & \\
\hline & Type & String & & \\
\hline & Measurement & Nominal & & \\
\hline & Role & Input & & \\
\hline \multirow[t]{6}{*}{ Valid Values } & Investigate Scene & & 2 & $2.0 \%$ \\
\hline & Question Subject & & 4 & $4.0 \%$ \\
\hline & Shots Fired & & 2 & $2.0 \%$ \\
\hline & Surveillance & & 3 & $3.0 \%$ \\
\hline & Suspicious Behavior & & 3 & $3.0 \%$ \\
\hline & $\begin{array}{l}\text { Unrelated Stop and } \\
\text { Question }\end{array}$ & & 1 & $1.0 \%$ \\
\hline Missing Values & 0 & & 85 & $85.0 \%$ \\
\hline \multicolumn{5}{|l|}{ traffic_stop_reason } \\
\hline & & Value & $f$ & $\%$ \\
\hline \multirow[t]{4}{*}{ Standard Attributes } & Label & Traffic Stop Reason & & \\
\hline & Type & Numeric & & \\
\hline & Measurement & Nominal & & \\
\hline & Role & Input & & \\
\hline \multirow[t]{7}{*}{ Valid Values } & 1 & Traffic Violation & 8 & $8.0 \%$ \\
\hline & 2 & Detain Suspect & 3 & $3.0 \%$ \\
\hline & 3 & Stolen Vehicle & 2 & $2.0 \%$ \\
\hline & 4 & Question Suspect & 1 & $1.0 \%$ \\
\hline & 5 & Loud Music & 1 & $1.0 \%$ \\
\hline & 6 & Suspicious Activity & 1 & $1.0 \%$ \\
\hline & 7 & Suspended License & 1 & $1.0 \%$ \\
\hline Missing Values & System & & 83 & $83.0 \%$ \\
\hline
\end{tabular}


serve_warrant_type

\begin{tabular}{lllrr}
\hline & & Value & $f$ & $\%$ \\
\hline Standard Attributes & Label & Warrant Type & & \\
& Type & Numeric & \\
& Measurement & Nominal & & \\
& Role & Input & 6 & $6.0 \%$ \\
& 1 & Arrest & 2 & $2.0 \%$ \\
& 2 & Search & 1 & $1.0 \%$ \\
\hline Valid Values & 3 & Protective/Eviction & 91 & $91.0 \%$ \\
\hline
\end{tabular}

signs_of_mental_illness

\begin{tabular}{lllll}
\hline & & Value & $f$ & $\%$ \\
\hline Standard Attributes & Label & $<$ none $>$ & & \\
& Type & Numeric & & \\
& Measurement & Nominal & & \\
& Role & Input & 76 & $76.0 \%$ \\
& 0 & False & 24 & $24.0 \%$ \\
\hline Valid Values & 1 & True & & \\
& & & & \\
\hline
\end{tabular}

mental_health

\begin{tabular}{lllrr}
\hline & & Value & $f$ & $\%$ \\
\hline Standard Attributes & Label & $<$ none & & \\
& Type & String & \\
& Measurement & Nominal & & \\
& Role & Input & 1 & $1.0 \%$ \\
& Bi Polar & & 1 & $1.0 \%$ \\
& Dementia & & 3 & $3.0 \%$ \\
& Depression & & $2.0 \%$ \\
& Off Meds & & 4 & $4.0 \%$ \\
& PTSD & 3 & $3.0 \%$ \\
& Schizophrenia & & 3 & $3.0 \%$ \\
& Suicidal & & $7.0 \%$ \\
\hline Missing Values & Unspecified & & 76 & $76.0 \%$ \\
\hline
\end{tabular}

\section{resistance}

\begin{tabular}{lllrr}
\hline & & Value & $f$ & \\
\hline Standard Attributes & Label & Resistance & \\
& Type & String & \\
& Measurement & Nominal & & \\
\hline & Role & Input & 12 & $12.0 \%$ \\
& Assault Officer & & $9.0 \%$ \\
& Barricade & & 11 & $11.0 \%$ \\
& Fled in Vehicle & & 16 & $16.0 \%$ \\
& Fled on Foot & 14 & $14.0 \%$ \\
& Refused Orders & & 24 & $24.0 \%$ \\
& Threatened Officer & & 14 & $14.0 \%$ \\
\hline
\end{tabular}


Sofficer_time_on_force

\begin{tabular}{llllr}
\hline & & Value & $f$ & $\%$ \\
\hline Standard Attributes & Label & Officer time on force & & \\
& Type & Numeric & & \\
& Measurement & Nominal & & \\
& Role & Input & 5 & $9.6 \%$ \\
& 1 & 1 year & 7 & $13.5 \%$ \\
Valid Values & 2 years & 3 & $5.8 \%$ \\
& 2 & 3 years & 2 & $3.8 \%$ \\
& 4 & 4 years & 5 & $9.6 \%$ \\
4 & 5 years & 2 & $3.8 \%$ \\
& 5 & 6 years & 2 & $3.8 \%$ \\
6 & 7 years & 3 & $5.8 \%$ \\
& 7 & 8 years & 3 & $5.8 \%$ \\
8 & 9 years & 1 & $1.9 \%$ \\
& 11 years & 4 & $7.7 \%$ \\
& 11 & 12 years & 2 & $3.8 \%$ \\
12 & 13 years & 4 & $7.7 \%$ \\
& 13 & 2 & $3.8 \%$ \\
& 15 & 16 years & 1 & $1.9 \%$ \\
16 & 17 years & 3 & $5.8 \%$ \\
& 17 & 19 years & $1.9 \%$ \\
& 19 & 24 years & 2 & $3.8 \%$ \\
\hline
\end{tabular}


Appendix B: Case Summaries

Table B1: Case Summaries for Black Subjects

\begin{tabular}{|c|c|c|c|c|c|}
\hline \# & name & age & date & city & state \\
\hline 1 & Kavonda Earl Payton & 39 & $2015-01-15$ & Aurora & $\mathrm{CO}$ \\
\hline 2 & Isaac Holmes & 19 & $2015-01-21$ & St. Louis & MO \\
\hline 3 & Dewayne Deshawn Ward & 29 & $2015-02-03$ & Antioch & CA \\
\hline 4 & Lavall Hall & 25 & 2015-02-15 & Miami Gardens & FL \\
\hline 5 & Douglas Harris & 77 & $2015-02-20$ & Birmingham & $\mathrm{AL}$ \\
\hline 6 & Dexter Pernell Bethea & 42 & 2015-04-08 & Valdosta & GA \\
\hline 7 & Jeffrey Kemp & 18 & 2015-04-17 & Chicago & IL \\
\hline 8 & D'Angelo Stallworth & 28 & $2015-05-12$ & Jacksonville & FL \\
\hline 9 & Kris Jackson & 22 & 2015-06-15 & South Lake Tahoe & CA \\
\hline 10 & Kawanza Beaty & 23 & 2015-07-04 & Newport News & VA \\
\hline 11 & Edward Foster III & 35 & 2015-07-16 & Homestead & FL \\
\hline 12 & Bryan Keith Day & 36 & $2015-07-25$ & Las Vegas & NV \\
\hline 13 & Earl Jackson & 59 & $2015-07-25$ & Micanopy & FL \\
\hline 14 & Shamir Terrel Palmer & 24 & 2015-08-08 & Summerville & $\mathrm{SC}$ \\
\hline 15 & Redel Jones & 30 & 2015-08-12 & Los Angeles & CA \\
\hline 16 & Bertrand Davis & 42 & 2015-08-27 & Dallas & TX \\
\hline 17 & James Marcus Brown & 25 & 2015-08-29 & North Las Vegas & NV \\
\hline 18 & Felix Kumi & 61 & $2015-08-28$ & Mount Vernon & NY \\
\hline 19 & Cedric Maurice Williams & 33 & 2015-09-01 & Bluefield & WV \\
\hline 20 & India Kager & 28 & 2015-09-05 & Virginia Beach & VA \\
\hline 21 & Tyrone Holman & 37 & 2015-09-09 & Kansas City & MO \\
\hline 22 & Brandon Foy & 29 & 2015-09-10 & Indianapolis & IN \\
\hline 23 & Dominic Hutchinson & 30 & $2015-10-24$ & Cathedral City & $\mathrm{CA}$ \\
\hline 24 & Marcus Meridy & 44 & 2015-11-18 & Berrien County & MI \\
\hline 25 & Nicholas Robertson & 28 & 2015-12-12 & Lynwood & $\mathrm{CA}$ \\
\hline 26 & Bobby Daniels & 48 & $2015-12-21$ & Douglasville & GA \\
\hline 27 & Daquan Antonio Westbrook & 18 & 2015-12-24 & Charlotte & $\mathrm{NC}$ \\
\hline 28 & Bruce Kelley & 37 & 2016-01-31 & Wilkinsburg & PA \\
\hline 29 & Calin Roquemore & 24 & 2016-02-13 & Beckville & TX \\
\hline 30 & Rico Don Rae Johnson & 28 & 2016-04-18 & Greenbelt & MD \\
\hline 31 & Demarcus Semer & 21 & 2016-04-23 & Fort Pierce & FL \\
\hline 32 & Charlin Charles & 25 & 2016-05-01 & Orlando & FL \\
\hline 33 & Willie Tillman & 33 & 2016-04-23 & Fayetteville & $\mathrm{AR}$ \\
\hline 34 & Lyndarius Cortez Witherspoon & 27 & 2016-06-11 & Tupelo & MS \\
\hline 35 & Jai Lateef Solveig Williams & 35 & 2016-07-02 & Asheville & $\mathrm{NC}$ \\
\hline 36 & Philando Castile & 32 & 2016-07-06 & Falcon Heights & $\mathrm{MN}$ \\
\hline 37 & Jawari Porter & 25 & 2016-08-07 & Cincinnati & $\mathrm{OH}$ \\
\hline 38 & Michael Thompson & 38 & 2016-09-02 & St. Louis & $\mathrm{MO}$ \\
\hline 39 & Terrence Sterling & 31 & 2016-09-11 & Washington & $\mathrm{DC}$ \\
\hline 40 & Ivory C. Pantallion & 36 & $2016-11-22$ & Baytown & TX \\
\hline 41 & Jamal Parks & 32 & 2017-01-06 & Deerfield & IL \\
\hline 42 & Keith Price & 21 & 2017-04-19 & Wilmington & $\mathrm{DE}$ \\
\hline 43 & Corsean Lewis & 17 & $2017-06-02$ & Chicago & IL \\
\hline 44 & Dejuan Guillory & 27 & 2017-07-06 & Mamou & LA \\
\hline 45 & Deltra Henderson & 39 & 2017-07-27 & Homer & LA \\
\hline 46 & Ricky Ard & 55 & $2017-08-29$ & Evansville & IN \\
\hline 47 & Tyrell Dewayne Pinkston & 28 & 2017-09-30 & Palatka & $\mathrm{FL}$ \\
\hline 48 & Marquis "Bubba" Jones & 27 & 2017-10-01 & West Burlington & IA \\
\hline 49 & Paul Jones & 25 & 2017-11-09 & Salisbury & $\mathrm{NC}$ \\
\hline 50 & Jean Pedro Pierre & 42 & $2017-12-06$ & Lauderdale Lakes & FL \\
\hline
\end{tabular}


Table B2: Case Summaries for White Subjects

\begin{tabular}{|c|c|c|c|c|c|}
\hline \# & name & age & date & city & state \\
\hline 1 & Jason Moncrief Carter & 41 & $2015-02-21$ & Ruidoso & NM \\
\hline 2 & Justin Tolkinen & 28 & 2015-03-16 & St. Paul & MN \\
\hline 3 & Phillip Burgess & 28 & 2015-04-09 & Boiling Springs & $\mathrm{SC}$ \\
\hline 4 & Daniel Davis & 58 & 2015-04-25 & Clermont & FL \\
\hline 5 & Stephen Cunningham & 47 & 2015-05-10 & Tacoma & WA \\
\hline 6 & Kenneth Lanphier & 48 & 2015-06-17 & Hobbs & NM \\
\hline 7 & Michael Holt & 35 & 2015-07-05 & Austin & $\mathrm{TX}$ \\
\hline 8 & Richard Munroe & 25 & 2015-07-05 & Austin & TX \\
\hline 9 & Rocco Joseph Palmisano & 50 & 2015-07-09 & Parowan & UT \\
\hline 10 & Samuel Smith & 27 & 2015-07-17 & Seattle & WA \\
\hline 11 & William Evans & 28 & $2015-08-28$ & Spanish Fork & UT \\
\hline 12 & Charles Robert Shaw & 76 & 2015-09-01 & Twinsburg & $\mathrm{OH}$ \\
\hline 13 & Mark Gary & 50 & 2015-09-17 & Beaverton & MI \\
\hline 14 & Jerrald Wright & 56 & 2015-09-20 & Shelbyville & IN \\
\hline 15 & Chris Nichols & 24 & 2015-11-21 & Colbert & OK \\
\hline 16 & Erica Lauro & 22 & 2015-12-18 & Northwood & $\mathrm{OH}$ \\
\hline 17 & Kenneth Stephens & 56 & $2015-12-22$ & Burlington & VT \\
\hline 18 & Scott Scanlon & 52 & 2016-01-27 & Mountain Pine & AR \\
\hline 19 & Travis Boyd Bradley & 36 & 2016-03-02 & Bel Air & MD \\
\hline 20 & Daniel J. Wooters & 38 & 2016-03-15 & Evansville & IN \\
\hline 21 & Angel Montion & 33 & 2016-03-30 & Los Angeles & $\mathrm{CA}$ \\
\hline 22 & Mark Daniel Bess & 33 & 2016-04-30 & Spanish Fork & UT \\
\hline 23 & Steve Godfrey & 69 & 2016-05-11 & Byng & OK \\
\hline 24 & Christopher Michael Moran & 31 & 2016-06-05 & Cape Coral & FL \\
\hline 25 & Joshua Sciscm & 33 & 2016-06-13 & Schenectady & NY \\
\hline 26 & Sergey Makarenko & 17 & 2016-06-18 & Carmichael & CA \\
\hline 27 & Christy Sheats & 42 & 2016-06-24 & Fulshear & TX \\
\hline 28 & Dylan Papa & 25 & 2016-09-06 & Phoenix & $\mathrm{AZ}$ \\
\hline 29 & Kristofer Daniel Youngquist & 45 & $2016-10-23$ & Peterson & MN \\
\hline 30 & Daniel Riedmann & 36 & 2016-12-07 & Sioux City & IA \\
\hline 31 & Scott Laurance Gilpin & 47 & 2017-01-14 & Austin & TX \\
\hline 32 & James Stephen McMullen & 45 & 2017-02-10 & Bethany & OK \\
\hline 33 & William Dwayne Darby & 39 & $2017-02-25$ & Lumpkin & GA \\
\hline 34 & Daniel Donarski & 58 & 2017-03-16 & Deltona & FL \\
\hline 35 & Richard Alexander Tilley & 28 & 2017-03-27 & Montgomery Village & MD \\
\hline 36 & Jeffrey Findlay & 30 & 2017-04-10 & Cleveland & $\mathrm{OH}$ \\
\hline 37 & Charles Shands & 33 & 2017-04-14 & Spanaway & WA \\
\hline 38 & Hayden J. Stutz & 24 & $2017-05-24$ & Canton & $\mathrm{OH}$ \\
\hline 39 & David Eric Ufferman & 56 & $2017-03-26$ & Delray Beach & FL \\
\hline 40 & Michael Zennie Dial II & 33 & 2017-04-17 & Clarksville & $\mathrm{TN}$ \\
\hline 41 & Douglas West & 46 & 2017-07-04 & Richland & WA \\
\hline 42 & Aaron Payne & 33 & 2017-08-04 & Surfside Beach & $\mathrm{SC}$ \\
\hline 43 & Thomas Justin Walton & 32 & 2017-08-19 & Homewood & AL \\
\hline 44 & Roger Helgerson & 45 & 2017-09-01 & Mount Hope & WI \\
\hline 45 & Michael Culhane & 50 & 2017-09-08 & Monett & MO \\
\hline 46 & Kevin Anthony Battaglia & 33 & 2017-10-02 & Parkton & $\mathrm{NC}$ \\
\hline 47 & Glenn Southwood Jr. & 46 & 2017-10-08 & Pinetop-Lakeside & $\mathrm{AZ}$ \\
\hline 48 & William Freddy Carter Jr. & 31 & $2017-11-26$ & Huntsville & $\mathrm{AL}$ \\
\hline 49 & James Newman & 69 & 2017-12-09 & Rose Bud & AR \\
\hline 50 & Robo Raikoglo & 30 & $2017-12-26$ & Desert Hot Springs & CA \\
\hline
\end{tabular}

